\title{
EREBEA
}

Revista de Humanidades

y Ciencias Sociales

Núm. 5 (2015), pp. 37-69

ISSN: 0214-0691

\section{YAZDEGARD I y BAHRAM GUR: ¿DOS REYES JUDÍOS DE LA PERSIA SASÁNIDA DEL SIGLO V D.C.?}

\author{
Narges Rahimi Jafari \\ Universidad de Granada
}

RESUMEN

En este artículo destacaremos la alta posición que adquirieron los representantes de la fe estatal dentro de los apartados del poder sasánida y el peligro que sentían de parte de otras religiones presentes en Persia, como el caso concreto del judaísmo. Religión que se encontraba dentro de las más rechazadas en los textos religiosos persas. Mencionamos algunas de las razones que podrían explicar esta visión negativa hacia el judaísmo. Después partiendo del relato de las fuentes perso-islámicas, especialmente la obra de Ferdosi, el Shahnameh (= Libro de los Reyes), abordaremos la cuestión de la fe de Yazdegard I y su hijo Bahram V. Destacaremos nuestras suposiciones sobre la posible conversión de Yazdegard I al judaísmo y según los datos obtenidos afirmaremos que su hijo Bahram era uno de los seguidores de esta religión semita.

Palabras Clave

Yazdegard I; Bahram V; judaísmo; La religión sasánida; Imperio Sasánida;

Fecha de recepción: 1 de junio de 2015

Fecha de aceptación: 30 de octubre de 2015
Abstract

This article deals with the outstanding status of the authorities of Zoroastrianism, the national religion of Sasanian Persia, in the Sasanian Empire. It also addresses the threat they faced from the other religions of Persia, such as Judaism. This latter religion was viewed very negatively in Zoroastrian books as among the most unbearable religions practiced in Iran. The study provides evidence which suggests an explanation for this negative view towards Judaism. In addition, the study tackles the question of the religion practiced by Yezdegerd I and his son Bahram V, on the basis of Arabic and Persian sources, amongst others the Shahnaheh of Ferdowsi. It discusses in more detail the religion practiced by Yazdegerd and argues that he showed sympathy towards Judaism. The article also argues that. according to the evidence that the sources provide, Bahram $\mathrm{V}$ was a follower of this Semitic religion.

\section{KeYwordS}

Yazdgerd I; Bahram V; judaism; The Sasanian religion; Sassanian Empire; 



\section{INTRODUCCIÓN}

Una de las características del Imperio Sasánida fue el establecimiento del zoroastrismo o el mazdeísmo como religión oficial de Persia. La unión entre el poder político de Iranshahr ${ }^{1}$ y esta religión se efectuó desde el inicio de la formación del Imperio sasánida ${ }^{2}$. El Estado persa se identificaba así con una única religión mucho antes de que lo hiciera Roma con el cristianismo. Comenzaba una simbiosis entre los representantes de la fe estatal sasánida y la aristocracia persa. Por un lado, el sistema político era legitimado por los conceptos de la religión estatal, que servían para interpretar y ordenar el sistema social, justificando la preeminencia del clan sasánida. Y por otra, los reyes otorgaban a los representantes de esta fe, libertad suficiente para intervenir en los aspectos jurídicos, educativos, sociales -a veces incluso políticos- del pueblo persa. Esta religión habría de llegar a funcionar como telón de fondo ideológico, determinando las actitudes sociales, políticas, etc. del pueblo de Iranshahr no solo a lo largo del período sasánida (ss. III-VII d.C.), sino incluso en épocas posteriores, cuando Persia había sido incorporada al mundo islámico.

1 El término Iranshahr, según Touraj Daryaee, fue desarrollado durante la época sasánida por los líderes religiosos para explicar el conjunto territorial que se encontraba bajo el poder de la aristocracia militar. Véase: Touraj Daryaee, Sasanian Persia, The Rise and Fall of an Empire. Londres y Nueva York: I. B. Tauris, 2009, p. 45.

2 Arthur Emanuel Christensen, L'Iran sous les Sassanides. Traducido al persa por Rashid Yasami, editado por Hasan Rezai Bagh Beidi, Teherán: Sedaye Moaser, 2005, pp. 68 y 100; Abdol-Hosein Zarrinkoob y Roozbeh Zarrinkoob, تاريخ ايران باستان (4) تاريخ سياسى ساسانيان historia del Irán antiguo (4) La historia política de los sasánidas). Teherán: Samt, 2002, pp. 1 y 17-18; Touraj Daryaee, Sasanian..., p. 45. Al-Ṭabarī al destacar que Ardashir I (226 240/1 d. C.), fundador de la dinastía sasánida, eligió a un hombre llamado Faher como el Mowbedan mowbed, la máxima autoridad religiosa, hace referencia a esta medida de los sasánidas. Véase: Muhammad ibn Ŷarīr al-Ṭabarī, تاريخ طبرى اتناريخ الرسل و الملوك"La historia de al-Tabarī o «la historia de los profetas y reyes»). Traducido al persa por Abolghasem Payandeh, Teherán: Asatir, 1983, vol. II, p. 582. Según otra narración, un hombre llamado Mahan era el Mowbedan mowbed de Ardashir I. Abū 'Al̄̄ Muhammad ibn Muhammad Bal'amī, تاريخ بلعىى (= La historia de Bal 'amī). Editado por Mohammad Taghi Bahar, Teherán: Tabesh, 1974, vol. II, p. 878. 
La importancia de la unión entre religión sasánida y política quedó remarcada en cada uno de los textos pertenecientes a este periodo, que de una forma u otra hacen referencia a ella. En este sentido, نامه تنستر به كثتاسب (= La carta de Tanstar a Gashtaseb) señala que: «La religión y el reinado han nacido del mismo útero y por ello son inseparables. Procediendo su virtud, corrupción, salud y firmeza de la misma naturaleza»». Otra obra, دين S = Los actos de la religión) aplica esta definición general al contexto específicamente iranio, destacando que: «El respeto del rey iranio <sólo> proviene de la religión <irania $>$; adorar a Ahura Mazda $<y$ establecer $>$ el mazdeísmo será posible a través del rey $<$ iranio $>\gg{ }^{4}$. Esta última definición, además de resaltar la importancia de dicha unión, confiere a la religión sasánida un concepto nacional. Una fe que justifica la presencia del clan sasánida en el poder, al mismo tiempo que delimita y diferencia la identidad del pueblo iranio frente a sus vecinos, como el Imperio Romano en Occidente o China en Oriente 5 .

Obviamente, la defensa de una religión nacional como la sasánida por parte de los reyes, pasa por una creencia firme en la misma. Y ello, solo se consigue, tal y como se destaca en مبنوى خرد (= El espíritu de la Sabiduría), a través de una educación establecida a partir de los principios de esa $\mathrm{fe}^{6}$, en este caso la religión estatal sasánida, iniciada desde los primeros momentos de la vida y transmitida generalmente por unos padres que también la practican. Sin embargo, en la historia sasánida se encuentran casos que desmienten lo anterior, como el de Bahram V (420/1 - 438/9 d. C.), conocido con el apodo de Gur por haber dado muerte a un león y un onagro

3 Anónimo, نامه تنستر به كثتناسب (= La carta de Tanstar a Gashtaseb). Editado por Mojtaba Minovi, anexos recopilados por Mojtaba Minovi y Mohammad Esmail Rezvani, Teherán: Kharazmi, 1975, p. 53. Consulten también: Abū 'Alī Ḥasan ibn 'Alī Nezamolmolk, سيروالملوك: (= La trayectoria de los reyes). Teherán: Bongah-e Tarjomeh va Nashr-e-Ketab, 1968, p. 80. En relación con la importancia de la unión entre la religión y el poder para los sasánidas, véase también: 'Alī ibn al-Ḥusayn al-Mas'ūdīi مروج الذهب (= Prados de oro). Traducido al persa por Abolghasem Payandeh, Teherán: Elmi va Farhangi, 2003, vol. I, pp. 243 y 247; 'Abd al Malīk ibn Muḥammad ibn Ismaāl Ta'alabī, غرر أخبار ملوك فارس (= La historia de reyes persas). Traducido al persa por Mohammad Fazaeli, Teherán: Noghreh, 1989, pp. 304 y 305.

4 Anónimo, دين كرد (= Los actos de la religión). Recopilado por Azar Farnabagh Farrokhzad y Azarbad Omid, traducido al persa por Ferydoon Fazilat, Teherán: Farhang-eDehkhoda, 2002, vol. III, primera parte, p. 99.

5 En relación con la función de la religión nacional, véase: Max Weber, Economía y sociedad, Esbozo de sociología comprensiva. Editado por Johannes Winchelmann, traducido al español por José Medina Echavarría, Juan Roura Parella, Eugenio Ímaz, Eduardo García Máynez, José Ferrater Mora, Madrid: El fondo de cultura económica, 2002, pp. 338 y 371.

6 Anónimo, مينوى خرد =El espíritu de la Sabiduría). Traducido al persa por Ahmad Tafazoli, Teherán: Bonyad-e Farhang-e Iran, 1975, p. 27. 
con la misma flecha ${ }^{7}$, cuya madre no seguía la religión sasánida. El nombre كهن نرين منن " جغر افياى ايران باستنان El más arcaico texto de la geografía histórica del Irán antiguo)», sin dejar lugar a equívocos:

Shushindojt (Shirindojt), la mujer de Yazdegard, hijo de Sapor, levantó las provincias de Shush [Susa] y Shushtar; ella fue la hija de Reš Galutā (Exilarca), rey de judíos y la madre de Bahram Gur $\left(\right.$ Bahram V) ${ }^{8}$.

El padre de Shushindojt, casada con el rey persa Yazdegard I (399-420/1 d. C), era el líder judío de la diáspora babilonia. A pesar de que este aspecto sea considerado por Frye como un mero cuento folklórico ${ }^{9}$, lleva a pensar que esta mujer bien pudo influir en el credo religioso de su marido y sobre todo en el de su hijo Bahram. Porque, según Ruiz Morell, es a partir del siglo II d.C. cuando, el judaísmo empezó a transmitirse por vía materna ${ }^{10}$. Por ello, Daryaee considera a Bahram como un rey judío para los correligionarios de su madre y un legítimo rey para los que seguían la fe estatal $^{11}$. Esto lleva a otros investigadores como Malekzadeh a plantearse la posibilidad de que Bahram fuera un príncipe judío ${ }^{12}$. Sin embargo, pese a

7 Bal'amī,... تاريخ (= La historia...), vol. II, pp. 930-931; Ta Ta historia...), p. 351. Véase también: Al-Ṭabarī,...ناريخ (= La historia...), vol. II, p. 616. Ferdosi también narra esta historia, sin embargo en otra parte destaca que este apodo, el gur, fue dado a Bahram por su gran habilidad en la caza de leones y onagros. Abolghasem Ferdosi, (=Libro de los reyes, texto crítico). Editado por M. N. Osmanov, supervisado por A. Noushin, Moscú: Danesh, 1968, vol. VII, pp. 275-276 y 332.

8 Ardeshir Khodadadian, كهن ترين منن جغر افياى تاريخى اير ان باستان) El más arcaico texto de la geografía histórica del Irán antiguo)», en فصلنامه رشد آموزش تاريخ (= Revista trimestral del fomento de la educación histórica). Número V, Teherán, 2001, pp. 46-50, espec. 49. Lo que aparece entre corchetes es una aclaración nuestra. También se ha dicho que Susa fue levantada por Sapor II (309/10 - 379 d. C.), véase: Ta alabī,... غرد (= La historia ...), p. 338. Incluso según otras versiones históricas ambas ciudades, Susa y Shushtar, fueron erigidas por Sapor II, véase: Ibn al- Baljī, فارسنامه (= Sobre los persas). Editado por Gay Le Strange y

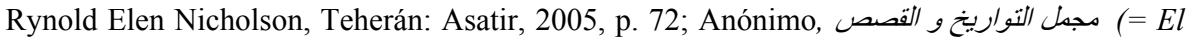
conjunto de historias y cuentos). Editado por Mohammad Taghi Bahar, Teherán: Kalaleh Khavar, 2004, pp. 63 y 64.

9 Richard Nelson Frye, The history of ancient Iran. Múnich: Beck, 1983, p. 319.

10 Olga Ruiz Morell, «Las mujeres judías, transmisoras de la tradición a la luz de la

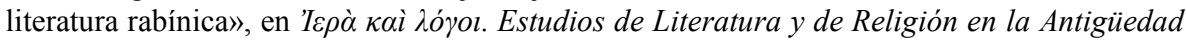
tardía. Zaragoza: Libros Pórtico, 2011, pp. 77-96, espec. 90.

11 Touraj Daryaee, Sasanian..., p. 78.

12 Véase: Soodabeh Malekzadeh, «A Historiographical Study of The Life and Reign of Bahram V» en http://www.sasanika.org/wp-content/uploads/GradPaper6-MalekzadehbahramV-historiography.pdf. California, 2013, pp. 1-10, espec. p. 2. 
estos datos y suposiciones, la información transmitida por las fuentes persoislámicas, especialmente la obra de Ferdosi, el Shahnameh (= Libro de los Reyes), muestran una realidad muy distinta respecto al credo religioso de Bahram. Además en esta obra, el poeta nacional iraní no se pronuncia de manera clara sobre la fe que profesaba Yazdegard I.

En este estudio se intentará abordar la cuestión de la fe practicada por estos dos reyes. Para ello partiremos del relato de las fuentes persoislámicas, analizando los datos aportados por los textos religiosos persas y los estudios relevantes realizados sobre los sasánidas. Pero la base principal serán las narraciones de Ferdosi, por la importante carga ideológica que contienen. Hay que subrayar que este poeta, según Safa, pertenecía al movimiento de la Šu'ūbiyya ${ }^{13}$ y como tal, resaltaba las virtudes del pueblo persa frente a la inferioridad árabe. Safa tras anotar este dato sobre Ferdosi y su obra concluye su estudio subrayando que este poeta no solo consideraba a los persas y sus costumbres superiores a los árabes, sino que a cualquier otro pueblo $^{14}$. Estamos de acuerdo con esta última reflexión acerca de Ferdosi y destacamos que este rasgo del Shahnameh se percibe en todos sus aspectos, pero sobre todo cuando los persas se enfrentan a sus enemigos. Además la obra de Ferdosi, según G. Fowden, supone una reconstrucción de la Historia épica de Persia como respuesta a los relatos sobre la conquista árabe, teniendo muy presente el futuro de su pueblo ${ }^{15}$.

Teniendo en cuenta estos datos sumamente importantes para evaluar el carácter y alcance de la obra de Ferdosi, nuestro estudio debe partir de unas breves anotaciones sobre la presencia judía en Persia, para pasar inmediatamente a evaluar la imagen del judaísmo entre la clase religiosa de la Persia sasánida. Todo ello encaminado hacia el objetivo de tratar de dilucidar si hubo o no dos reyes judíos sentados en el trono de Iranshahr.

\section{LOS JUDÍOS EN PERSIA}

La historia de la destrucción del Primer Templo a manos de los babilonios es de sobra conocida. No obstante, merece la pena hacer mención a cómo estos hechos son contados por los historiadores musulmanes de la Edad Media. Una de las tradiciones más interesante es la transmitida por Hīšam ibn Muhammad, recogida a su vez por al-Ṭabarī, a continuación la

13 Sobre este movimiento, véase: S. Enderwitz, «al-Shu'ūbiyya», en $E I^{2}$, vol. 9. LeidenLondres: E. J. Brill, 1997, pp. 513-516.

14 Zabihollah Safa, شعوبيت فردوسى (= Sobre la tendencia de Ferdosi hacia la Šu’ūbiyya», en (s) (= Mehr). Teherán, 1934, números XVII y XVIII, pp. 619-623.

15 Véase: G. Fowden, Before and after Muhammad. The First Millennium Refocused. Londres: Princeton, 2014, pp. 199-200. 
describimos de forma breve: Las fuerzas de Nabucodonosor, al que convierte en virrey de Lohrasb, rey persa, avanzaron hasta Jerusalén, estableciendo un pacto con el rey de esta tierra, uno de los descendientes de David, al que obligaron a entregarles rehenes. Esta deshonra llevó al pueblo de Israel a acabar con su rey. Como represalia, Nabucodonosor ejecutó a los rehenes, tomó Jerusalén y sometió a cautiverio a muchas mujeres y niños. Seguidamente invadió Palestina y Judea, donde también se hizo con numerosos esclavos, entre los que estaba el profeta Daniel, que fueron deportados a Babilonia ${ }^{16}$. Según al-Ya'qūbī: «El número de cautivos, era 18.000 , de los cuales unos 1.000 eran líderes religiosos $\rangle^{17}$. Durante la época de Vistasp, sucesor de Lohrasb, le fue ordenado a uno de los descendientes de David reconstruir Jerusalén y se hizo posible el regreso de los israelitas a su antigua patria ${ }^{18}$.

Por otra parte destaca al-Ṭabarī que los judíos asentados en Babilonia permanecieron en esta tierra hasta que Ciro - quien también tenía una madre judía-, hizo efectivo su regreso a Jerusalén ${ }^{19}$. Según señala Pirnia, quienes

16 Al-Ṭabarī,...ناريخ (= La historia...), vol. II, pp. 453-455. Según al-Ya'qūbī uno de los reyes de Babilonia atacó a Jerusalén, esclavizó al rey de esta ciudad y le obligó a pagarle impuestos. Después atacó Palestina, la destruyó y asentó a sus pobladores en Babilonia. Sin embargo, después mandó que reconstruyeran la ciudad de Israel, es decir, Jerusalén. Aḥmad ibn Isḥaq al-Ya'qūbī, تاريخ بعقوبى (= La historia de al-Ya'qūbì). Traducido al persa por Mohammad Ebrahim Ayati, Teherán: Elmi va Farhangi, 2003, vol. I, p. 75.

17 Al-Ya'qūbī,....تاريخ (= La historia...), vol. I, p. 78.

18 Al-Ṭabarī,.... تاريخ (= La historia ...), vol. II, p. 455. En la tradición islámica existen discordancias en torno al nombre del rey que permitió el regreso de los judíos a Palestina y cómo fueron los hechos. Según al-Ya'qūbī era el mismo Nabucodonosor quien por la intervención de su esposa judía hizo efectivo el regreso de ese pueblo a Jerusalén, véase: AlYa'qūbī,...تاريخ (= La historia...), vol. I, p. 79. Al-Dīnwarī señala que Bahman, hijo de Esfandiar, quien había contraído matrimonio con una judía llamada Irajat, fue quien llevó a cabo esta tarea. Según esta versión Bahman asignó el reinado de Siria al hermano de su esposa judía. Este último reconstruyó la ciudad de Elia y el Templo. Asimismo devolvió a los supervivientes judíos sus tesoros y permitió que regresaran a su antigua patria, véase: Abū Hanīfah Aḥmad ibn Dawūd al-Dīnwarī, آخبارُالطُّوال (= Noticias inquietantes). Traducido al persa por Mahmood Mahdavi Damghani, Teherán: Ney, 1994, p. 51. Véase también: Anónimo,... مجمل التواريخ (=El conjunto de historias...), p. 30.

19 Al-Ṭabarī,....تاريخ (= La historia...), vol. II, p. 452. Según Bal'amī, la madre judía de este Ciro -que hizo efectivo el regreso de los judíos a Jerusalén- fue Ester. Este rey según el mismo autor se convirtió al judaísmo. Bal'amī,...تاريخ (= La historia ...), vol. II, pp. 675-676. Otros autores también consideran una ascendencia materna judía para Ciro. AlMas'ūdīi,... مروج (= Prados...), vol. I, p. 225. En relación con esta medida de Ciro -hacer regresar a los judíos a Jerusalén- véase también: Mary Boyce, Zoroastrians, Their Religious Beliefs and Practices. Traducido al persa por Askar Bahrami, Teherán: Qoqnoos, 2009, p. 78; Moshir od-Dowleh Pirnia, بيران باستان: تاريخ مفصل ايران قديم از آغاز تا انقراض ساسانبان Irán antiguo: La historia completa del Irán antiguo desde sus comienzos hasta la caída de los sasánidas). Teherán: Dabir: Samir, 2007, vol. I, p. 320. 
regresaron a Palestina fueron los pobres ya que los adinerados prefrieron permanecer en Babilonia para seguir dedicándose a sus negocios ${ }^{20}$. De este modo, en Babilonia residiría una importante comunidad judía que, tras su desplazamiento forzado por Nabucodonosor, se arraigó en esta tierra y por intereses económicos la prefirió a su patria ancestral.

Shushtar y Susa, mencionadas en el fragmento anterior, eran dos ciudades de Persia en donde habitaban los judíos. Ambas, según lo apuntado anteriormente, fueron levantadas por la madre de Bahram V. Probablemente la reina Shushindohjt de cuyo nombre proviene la denominación de las ciudades, Susa y Shushtar, o al contrario, intentaría apoyar a sus correligionarios. Con estas medidas buscaría ampliar la presencia judía en el Imperio Persa. En relación con los judíos de Susa, al-Balādurī destaca que durante el periodo de la conquista, los musulmanes se encontraron con el cadáver de Daniel en esta ciudad, que había sido trasladado desde Babilonia para atraer las lluvias a aquella tierra seca ${ }^{21}$. Este dato atestigua la presencia judía en esta ciudad ya que solicitar ayuda divina utilizando como intermediario el cuerpo de un profeta judío, solo habría podido llevarse a cabo por aquellos que creían en esta religión.

En la provincia de Esfahán también habitaban gran número de judíos, tanto que una de las ciudades de esta provincia tenía por nombre Yahoodieh $^{22}$. Aunque según el geógrafo Yaqūt Ḥamawī este nombre fue dado a toda Esfahán por habitar en ella aquellos judíos cuyo hogar fue destruido por Nabucodonosor ${ }^{23}$. Todavía se conservan sinagogas pertenecientes a esta comunidad, los descendientes de aquellos inmigrantes judíos de la época antigua. Asimismo, este geógrafo musulmán habla de un pueblo en Jorasán, llamado Wasit Noghan que era conocido como «Wasit Judío» y de la existencia de un barrio en Gorgán con el nombre «Judío» ${ }^{24}$.

La información acerca de la presencia judía en Persia también se halla presente en el Shahnameh. En los versos de esta obra podemos entrever la proximidad de la mansión de un judío al lado de Hamoon ${ }^{25}$, lago que se encuentra en Sistán. Asimismo Christensen refleja la existencia en la misma

20 Moshir od-Dowleh Pirnia,...بران باستان (= Irán antiguo...), vol. I, p. 320.

21 Abū Ḥasan Aḥmad ibn Yaḥya al-Balad̄ūrī, فتوح البلدان (= La conquista de tierras). Traducido al persa por Mohammad Tavakol, Tehéran: Noghreh, 1954, p. 528. Sin embargo, según al-Dīnwarī el profeta Daniel falleció en Susa, véase: al-Dīnwarī,... خَار (خبار Noticias inquietantes...), p. 48.

22 Véase: Al-Balad̄ūrī,... فتوح (= La conquista ...), p. 441.

23 Yaqūt Ḥamawī, بركزيده مشترك ياقوت حموع (= Una selección común de Yaqūt Hamawī). Traducido al persa por Mohammad Parvin Gonabadi, Teherán: Amir Kabir, 2004, p. 187.

24 Yaqūt Hạawī,... بركزيد (= Una selección...), pp. 183 y 187.

25 Abolghasem Ferdosi,... شاهنامه (= Libro de los reyes...), vol. VII, p. 315. 
capital persa, Ctesifonte, de una comunidad judía ${ }^{26}$. Todos estos datos permiten afirmar que tras su desplazamiento forzado, el pueblo judío empezó a asentarse en las distintas ciudades y provincias persas, incluyendo las más septentrionales, convirtiéndose en un elemento más de la heterogénea sociedad de los distintos imperios persas.

\section{LA «AMENAZA DEL JUDAÍSMO»}

El proselitismo de lo que eran consideradas religiones extranjeras, fue considerado en el Wandidad (= La ley contra los daevas), una parte del Avesta, como el primer pecado imperdonable y para el cual estaba reservada la condena a muerte ${ }^{27}$. Sin embargo, era imposible frenar las influencias que otras religiones ejercían sobre los persas, debido a la continua convivencia de estos con judíos o cristianos, por citar sólo los dos monoteísmos. Este hecho se acentuaba más aún debido a los matrimonios mixtos, entre persas y nopersas, especialmente significativos cuando se daban en miembros de los estratos más altos de la sociedad persa, como la familia real. Uniéndose a la cúpula del poder mediante el matrimonio, individuos de uno $\mathrm{u}$ otro sexo, llevaban consigo la fe que profesaban al escenario político de Persia. Naturalmente, ellos, desde el poder político, intentaban proteger a sus correligionarios tanto en el territorio persa como en aquellas tierras que se encontraban bajo su influencia.

El apoyo que prestaron algunas figuras políticas a otras religiones, especialmente a uno de los dos monoteísmos, podría debilitar o acabar con la indiscutible hegemonía de la religión sasánida en el sistema político. Esta posibilidad inquietaba a los representantes de esta fe, porque tal y como dice مينوى خرد =El espiritu de la Sabiduría): «la religión más fuerte es la que cuenta con el apoyo del poder político»» ${ }^{28}$.

La confrontación de la religión estatal de la Persia sasánida con otras religiones profesadas en esta tierra y el miedo que sentían los representantes de la fe sasánida hacia la influencia que pudieran ejercer, se percibe a través de la lectura de los distintos textos religiosos. Uno de los ejemplos más destacados lo ofrece مبيوى خرد =El espiritu de la Sabiduría), en el cual la religión mazdeísta se presenta como la que ofrece las respuestas más claras y

26 Arthur Emanuel Christensen, L'Iran ..., p. 279.

(وستا كهن ترين سرودها و متنهاى ابران El Avesta, los más antiguos himnos y textos iranies).

Traducido y editado por Jalil Doostkhah, Teherán: Morvarid, 2006, vol. II, ونديداد (Wandidad), فركرد يانزدهم (= Capítulo XV), p. 825, párrafos I-II. El alma de todos aquellos que no respetan esta norma sufrirán castigos en el purgatorio. Anónimo, اردداوير اف نامهان (= La obra de Arda-Viraf)», en so (= Mehr). Traducido al persa por Rashid Yasami, Teherán, 1935, número III, pp. 241-248, espec. p. 248, párrafo. XLVII.

28 Anónimo,... مينوى (= El espíritu...), p. 27. 
precisas acerca de la vida terrena y ultraterrena, señalando las contradicciones que hay en las otras religiones, cuyos mensajes son además $\operatorname{confusos}^{29}$. En este sentido, دين كرد = Los actos de la religión) va un paso más allá al destacar que Iranshahr recibirá al Dios de la «Bondad y la Felicidad» solo a través de la justicia aria y el mazdeísmo, mientras que mediante los cultos no iranios se convertiría en un lugar para Dios de la Maldad y la Desgracia ${ }^{30}$.

Estas reflexiones acerca de la fe sasánida y sus relaciones con otras religiones aparecen incluso en el Avesta, en el que los seguidores de otras religiones son llamados ignorantes. Según esta obra, proceden del mundo de la Mentira, expresándolo con las siguientes palabras: « ¡Oh Mazda! Quien obedezca otra [orden distinta a esta], procede del mundo de la «mentira», es ignorante y llevará el mundo a la destrucción» ${ }^{31}$.

Además, los textos religiosos reflejan el daño que causaron las religiones extranjeras y sus prosélitos a la fe sasánida con las siguientes palabras:

\footnotetext{
Evidentemente las bases de Iranshahr son la pureza de sangre, la justicia, <la antigua $>$ religión mazdeísta; y las características desconocidas para <Iranshahr>, las cuales no son más que rasgos, religiones y tradiciones no iranias, las que han llegado a perjudicar la buena religión mazdeísta irania ${ }^{32}$.
}

Una de estas religiones no-iranias que amenazaba seriamente la posición de dominio disfrutada por la fe estatal fue el judaísmo. El rechazo del que fue objeto queda patente en los textos religiosos persas. Según دين كرد ) Los actos de la religión), esta fe, junto al maniqueísmo y la corriente sofista, eran consideradas tres religiones desviadas. El judaísmo entra en disputa con el mazdeísmo sobre los principios religiosos. El personaje principal de دين كرد (= Los actos de la religión) es un hirbad ${ }^{33}$ que en respuesta a aquellos judíos que habían criticado el mazdeísmo por considerar dos orígenes distintos para toda la existencia, la maldad y la bondad, pone en duda esta religión semita por afirmar que la maldad y la bondad, tienen un mismo origen. Según la lógica dualista del mazdeísmo, el hirbad no podía aceptar que el Sepandarminu, (= Sabiduría creciente) fuese la causa de maldades, ya que

29 Véase: Anónimo,... مينوى (= El espíritu ...), p. 28.

30 Anónimo,... دين (= Los actos...), vol. III, primera parte, p. 53.

31 (وستا (Evesta...). Traducido y editado por Jalil Doostkhah, vol. I, Yasna Hat LI, p. 79, párrafo X. Lo que aparece entre los corchetes es una aclaración del mismo texto.

32 Anónimo,... دين (= Los actos ...), vol. III, primera parte, p. 53.

33 En relación con el cargo de este líder religioso véase nota n. 57 . 
estas proceden del Zadarminu (= Ignorancia creciente) $)^{34}$. Naturalmente, desde la perspectiva del estamento religioso, una fe que atacaba las bases fundamentales de su religión, bajo ningún concepto habría de llegar a intervenir en las decisiones estatales.

Quizás uno de los puntos de conflicto más evidentes entre la religión sasánida y judaísmo girara en torno a la cuestión del enterramiento de cadáveres. Este ritual sagrado para estos, era un gran sacrilegio según los primeros. En Wandidad, la práctica de la inhumación era considerada como una de las creaciones de Ahrimán, tanto rechazo generaba que se prohibía enterrar el pelo y uñas cortadas. La razón esgrimida era que, de no respetar esta norma, aumentaría la fuerza de los daevas -antiguos dioses indoeuropeos detestados, según Pour Davood entre otros, por Zoroastro ${ }^{35}-\mathrm{y}$ el entierro era interpretado como una ofrenda a estos seres malignos ${ }^{36}$. Por ello, los persas a diferencia de cristianos y judíos, solían abandonar los cadáveres «en la cima de la montaña y a merced de perros y aves carroñeras ${ }^{37}$.

Los porqués de este ritual hay que buscarlos en el carácter animista de la religión sasánida ${ }^{38}$. Según Wandidad, existía entre los persas la creencia según la cual cuando una persona fallecía, un daeva llamado نسو (Nasu) -que según (آفرينش بنيادين) = Bondhesh, (el comienzo de la creación) provoca impureza $^{39}$ - penetraba en forma de mosca en el cadáver y permanecía en él hasta que los perros o aves carroñeras empezaban a mirar o devorarlo. En ese momento el daeva, bajo la misma forma de mosca, abandonaba el cadáver y regresaba hacia sus orígenes ${ }^{40}$. Desde la perspectiva de la religión irania, en caso del entierro, Nasu, la mentira, permanecería dentro del cuerpo

34 Anónimo,.. دين (= Los actos...), vol. III, segunda parte, pp. 136-139 y 237.

35 Véase: وستا كهن ترين كتاب آسمانى در زمان ايران باستان (2) =El Avesta, el más antiguo libro divino en el Irán antiguo). Traducido y editado por Ebrahim Pour Davoud, Teherán: Donyae

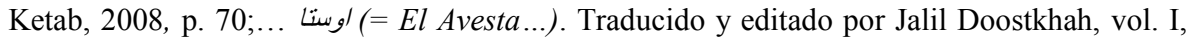
فروردين يشت La alabanza a Farvardin), p. 424, párrafo. LXXXIX; Arthur Emanuel Christensen, L Iran ..., pp. 14-15.

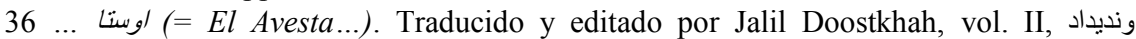
(Wandidad), فركرد اول (=Capítulo I), p. 662, párrafo XIII; فركرد هفده (= Capítulo XVII), p. 841, párrafos I-II.

ونديداد 37 (وستا ... El Avesta...). Traducido y editado por Jalil Doostkhah, vol. II, (Wandidad), فركرد ششم (= Capítulo VI), p. 727, párrafo XLV.

38 Véase la definición completa de las religiones animistas en: Max Weber, Economía y sociedad..., p. 351 .

39 Anónimo, بُند هِ (آفرينش بنيادين) = Bondhesh, (el comienzo de la creación). Recopilado por Farnabaq Dadeghi, traducido al persa por Mehrdad Bahar, Teherán: Toos, 1999, p. 121.

ونديداد, اوستا ... El Avesta...). Traducido y editado por Jalil Doostkhah, vol. II, (Wandidad), فركرد هفتم (= Capítulo VII), pp. 729-730, párrafos I-III. 
impurificando la tierra. El poder que esto les daba a los daevas en su lucha contra los dioses, según la cosmogonía zoroástrica, dependía enormemente del rango social del difunto, ya que no era lo mismo el cuerpo de un simple campesino que el de un noble ${ }^{41}$.

Otro de los puntos en torno a los que giraban las controversias entre rabinos y los líderes del mazdeísmo, era la práctica del incesto por parte de los persas y que horrorizaba a los judíos. En el دين كرد) Los actos de la religión), se ha conservado la disputa sobre el incesto mantenida entre un hirbad y un judío ${ }^{42}$. Asimismo, la transmisión por vía materna de la fe judía entraría en contradicción con las creencias persas acerca de la mujer, recogidas en los distintos textos religiosos. Un ejemplo del papel secundario de la mujer lo ofrece مبنوى خرد (= El espiritu de la Sabiduría) donde ni siquiera es considerada apta para dar testimonio ${ }^{43}$. En el Avesta se le ordena obedecer en todo a su marido ${ }^{44}$. Pero es en (بند هِش (آفرينش بنيادين) (= Bondhesh, (el comienzo de la creación), donde se llega al paroxismo de la misoginia, al calificar a la mujer de especie demoníaca ${ }^{45}$.

En nuestra opinión, sería inexplicable teniendo en cuenta los principios ético-religiosos de los sasánidas, que estos aceptaran que un credo religioso válido pudiera transmitirse a través de un ser de especie «demoníaca». Además, esta forma de transmisión de la religión, motivaría que el judaísmo constituyera para los representantes de la fe estatal sasánida una amenaza mucho mayor que cualquier otra religión. Bastaría que un rey contrajera el matrimonio con una judía, y sobre todo eligiera a su hijo como heredero al trono, para debilitar o acabar con la presencia de los líderes de la fe sasánida entre los principales dirigentes del Estado. Por esta razón el judaísmo se encontraría entre los credos que suscitarían un mayor rechazo. Por ello los representantes del mazdeísmo expresaron su consternación ante tal

41 Según Wandidad, a medida que aumenta el rango social de las personas, crece el número de aquellos que pueden llegar a impurificarse por Nasu. Eso mismo pasa con los animales muertos, de modo que el número de las personas que pueden llegar a impurificarse por Nasu, depende de la importancia del animal en la religión zoroástrica, pero siempre menos de las que pueden impurificarse por los cadáveres humanos. Sin embargo, el poder de Nasu para impurificar se reduce enormemente cuando se trata de todo aquel o aquello rechazado por el zoroastrismo como los malos y prostitutas. Véase:... وستا (g) (Evesta...). Traducido y editado por Jalil Doostkhah, vol. II, ونديداد (Wandidad), فركردينجم (=Capítulo V), parte VI, pp. 709-711, párrafos XXVII-XXXVI.

42 Véase: Anónimo,.. دين (= Los actos...), vol. III, primera parte, pp. 143-150. 43

Anónimo,... مبنوى (= El espiritu...), p. 56.

44 Véase:... اوستا (II (= El Avesta ...). Traducido y editado por Jalil Doostkhah, vol. II, p. 529, párrafo. IV.

45 Véase: Anónimo,... بُند هُش (= Bondhesh...), pp. 83-84. 
posibilidad en دين كرد (= Los actos de la religión), destacando que la llegada del judaísmo al poder, sometería el mundo al peor de los tiempos ${ }^{46}$.

Los líderes de la religión estatal no se limitaron a expresar su preocupación por la llegada de miembros de otras religiones como el judaísmo a las altas esferas del poder, sino que actuaron al respecto. Conscientes de que el peligro hacia su religión, provendría principalmente de los matrimonios mixtos, intentaron frenarlos mediante el establecimiento de distintas leyes. Sabemos que la sociedad sasánida se dividía en cuatro clases que según دين كرد Los actos de la religión) eran asimilables a distintas partes del cuerpo humano. La más importante era la cabeza, que se asemejaba a los representantes de la religión; en orden decreciente, le seguían las manos, representadas por los militares; el tronco lo conformaban los campesinos y finalmente las piernas eran los artesanos ${ }^{47}$. En base a esta división -tajante- de la sociedad, en la carta de Tanstar se prohibieron los matrimonios entre los miembros de los estratos altos y bajos de la sociedad irania $^{48}$. En esta obra, por medio de una anécdota, se explicitaba que el fruto de este tipo de uniones podía llegar a hacer mucho mal en el mundo ${ }^{49}$, justificando así el motivo de esta prohibición. دين كرد =Los actos de la religión) explica mejor esta ley y destaca que la libertad matrimonial mezclaría a los pueblos y como consecuencia se reduciría el culto de Ahura Mazda y aumentaría el culto a los daevas ${ }^{50}$. En línea con lo anteriormente expuesto sobre el término daevas, traemos a colación la definición que Ferdosi da: todo aquel mal hombre que no agradece a يزدان (yazdan) término éste que englobaría a todos los dioses del mundo mazdeísta. De modo, quien no siguiera a estas divinidades y/o se opusiera a ellas entraba en la categoría de daevas, de ahí que podamos afirmar que todas las religiones distintas a la fe sasánida, no tendrían otro calificativo para los seguidores de ella que culto a los daevas ${ }^{52}$.

46 Véase: Anónimo,... دين (= Los actos ...), vol. III, segunda parte, p. 218.

47 Anónimo,... دين (= Los actos...), vol. III, primera parte, p. 72. Véase también: Arthur Emanuel Christensen, L'Iran ..., p. 69.

48 Anónimo,... نامه تنستر (= La carta de Tanstar...), p. 65.

49 Véase: Anónimo,... نامه تنستر (= La carta de Tanstar...), p. 66.

50 Véase los detalles en: Anónimo,... دين (= Los actos...), vol. III, primera parte, pp. 1516.

51 Tú reconoce como daeva a todo

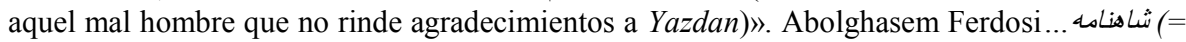
Libro de los reyes...). Editado por R. Aliev, E. Berthels, M. Osmanov, supervisado por A. Noushin, Moscú: Danesh, 1965, vol. IV, p. 310.

52 Christensen también considera que el término "daeva" llegó a aplicarse para denominar a las divinidades de los no mazdeístas: Arthur Emanuel Christensen, L Iran ..., p. 14. 
El rechazo hacia todas las religiones no-iranias se incrementa y en cierto modo se explica por el hecho de que quienes las profesaban pertenecían a los estratos más bajos de la sociedad sasánida. En el caso del judaísmo, sus principales prosélitos eran comerciantes, un oficio denominado como el más bajo en دين كرد (= Los actos de la religión) ${ }^{53}$. Por ello, prohibir el matrimonio entre las clases altas y bajas protegía el escenario político de su presencia, pero sobre todo de su religión. Al tiempo que rechazaban el matrimonio entre distintos estratos sociales, los magos alentaban las uniones incestuosas práctica rechazada por el judaísmo, tal y como ya apuntamos-, y la razón de ello podemos colegirla de la siguiente frase que se lee en دين كرد (= Los actos de la religión): «la práctica más dolorosa del hombre contra los daevas, es el incesto, ya que aumenta el ejército humano» ${ }^{54}$. Teniendo en cuenta que según El espiritu de la Sabiduría) sólo son hombres quienes creen en el mazdeísmo y no en otra religión ${ }^{55}$, unido al significado que tenía el concepto de daevas para los mazdeistas, la frase citada aludiría a que la práctica del incesto aumenta los seguidores del mazdeísmo frente a los daevas, es decir, todos aquellos que practican otras religiones distintas al mazdeísmo y que estaban proliferando en el seno de la sociedad sasánida ${ }^{56}$.

Pero ésta no era la única vía por la cual los magos protegían su estatus privilegiado en la organización social de Persia. La máxima autoridad religiosa, el Mowbedan mowbed (= el Mubed de mubedes) ${ }^{57}$ era quien tenía en sus manos la sucesión al trono. Según la Carta de Tanstar, narrando su información de forma resumida, el rey antes de morir estaba obligado a escribir el nombre de su sucesor en tres cartas secretas y dar una de ellas a la autoridad religiosa, otra a la cabeza de los magistrados, Mehtar Dabiran, y

53 Anónimo,... دين (= Los actos...), vol. III, primera parte, p. 122. Touraj Daryaee destaca que eran las minorías religiosas las que se dedicaban generalmente al comercio y por ello este oficio fue rechazado por los sasánidas. Touraj Daryaee, Sasanian..., pp. 48-49.

54 Anónimo,... دين (= Los actos...), ...vol. III, primera parte, p. 31.

55 Véase: Anónimo,... مينوى (= El espiritu...), p. 60.

56 Consulten también: Mary Boyce, Zoroastrians..., p. 81. Según lo expuesto por Touraj Daryaee esta práctica aseguraba el mantenimiento de la riqueza y la religión en la familia. Touraj Daryaee, Sasanian..., p. 64.

57 Los mubedes formaban la cúspide dentro de la jerarquía religiosa del zoroastrismo, a ellos los seguían los hirbades que eran guardianes de los templos del fuego, maestros en los himnos religiosos y los rituales y finalmente los dastvares que eran expertos en religión. Arthur Emanuel Christensen, L'Iran ..., pp. 83, 84-85. Los dastvares eran quienes dictaban órdenes religiosas. Véase: Anónimo,... دين (=Los actos...), vol. III, primera parte, pp. 32 y 43. Deducimos de las descripciones de otra fuente religiosa que los dastvares conocían el motivo de toda la creación. Véase: Anónimo,... يُند هِ (= Bondhesh...), p. 103. Los zoroástricos realizaban el arrepentimiento de sus pecados ante los dastvares. Véase: Anónimo,... مينوى (= El espíritu...), p. 69. Sobre el organigrama religioso dentro del sistema religioso sasánida, véase también: Touraj Daryaee, Sasanian..., pp. 43 y 44. 
la última al máximo representante de los generales del ejército, Spahbadan spahbad. Tras la muerte del rey, el Mowbedan mowbed se reunía con los otros dos, leían las cartas y sólo en caso de la afirmación de la máxima autoridad religiosa, se publicaba el nombre del futuro rey. En caso de su oposición, él se reunía con otros religiosos, se dedicaban a realizar una serie de plegarias y tras la oración nocturna, sólo aceptaban como rey a aquel cuyo nombre le hubiera sido revelado al Mowbedan mowbed por «la mismísima divinidad». Después, el nuevo rey empezaría su mandato confesando su absoluta fe en la religión zoroástrica ${ }^{58}$.

Una confirmación sumamente importante, ya que daba un poder enorme a los líderes de la religión, en concreto al Mowbedan mowbed, no sólo para destronar sino incluso para acabar con aquel rey que dejara de practicar el zoroastrismo. Según la misma fuente, los sasánidas ponían fin a la vida de herejes, castigo que se ejercía tras un año de gracia, tiempo durante el cual intentaban volver a encaminar al supuesto hereje al camino de la rectitud mediante consejos ${ }^{59}$.

No obstante, estas recomendaciones y normas política-religiosas establecidas para proteger la fe y el estatus de los representantes religiosos del mundo sasánida, no pudieron frenar el matrimonio entre seguidores de otras religiones y persas como fue el caso de la esposa judía de Yazdegard I.

\section{LA RELIGIÓN DE YAZDEGARD I Y BAHRAM GUR}

Existe una suerte de unanimidad entre los historiadores perso-islámicos, al calificar a Yazdegard I como بزه كر (= Malhechor). Según Ferdosi, narrando su versión de forma resumida, este rey habría empezado su regencia invitando a todos a adorar a Yazdan, a seguir a los mubedes, a no hacer daño a los pobres, etc. Sin embargo, al asentarse en el poder, siguiendo el relato del poeta del s. XI, el rey dejó de ser justo e hizo sufrir mucho a los mubedes. Continúa relatando que al transcurrir ocho años del reinado de Yazdegard nació su hijo Bahram, quien según el pronóstico de los astrólogos, le sustituiría en el trono. Ante esta noticia, el Mowbedan mowbed, el mago y el dastvar ${ }^{60}$, para evitar que el mal innato del padre se transmitiera al hijo, recomendaron a Yazdegard que mandara a Bahram fuera de Persia para que recibiera educación en una tierra donde hubiera

58 Anónimo,... نامه تنستر (= La carta de Tanstar ...), pp. 87-89. Este dato también aparece en: Arthur Emanuel Christensen, L'Iran ..., p. 192.

59 Anónimo,... نامه تنستر (- La carta de Tanstar...), p. 62; Abolghasem Ferdosi... شنامه (= Libro de los reyes...). Editado por E. Berthels, supervisado por A. Noushin, Moscú: Danesh, 1971, vol. IX, p. 34.

60 Véase al respecto la nota $\mathrm{n} .57$ de este mismo estudio. 
sabiduría. El Shahanshah aceptó esta propuesta y entre chinos, indios, romanos y árabes, eligió a este último pueblo para educar a su hijo ${ }^{61}$.

Al-T Tabarī, a diferencia de Ferdosi, no menciona nada de la intervención del estamento religioso en la toma de esta decisión por Yazdegard. Este historiador en una parte de su obra subraya que Yazdegard optó por enviar a su hijo a un lugar agradable y sin epidemias, al-Hīra, porque ninguno de sus hijos varones sobrevivía. En otra parte, relaciona el motivo de esta decisión con los pronósticos de los astrólogos, quienes le habían recomendado a Yazdegard que su hijo debería de ser amamantado en un lugar donde no hubiera persas ${ }^{62}$.

Volviendo al relato del Shahnameh, Ferdosi sigue narrando cómo Bahram al crecer entre los árabes, decidió volver a la corte persa en busca del cariño paterno. Pero pronto recibiría el desdén de Yazdegard. El tutor de Bahram, el rey de árabes, al enterarse de la situación del príncipe le envió dinero para animarlo y le recomendó tener paciencia y orar mucho, ya que no podría separar de Yazdegard su mal carácter. Bahram, siguiendo los consejos de su tutor, sobrellevaba la situación, dedicándose a las oraciones, hasta que fue encerrado por orden de Yazdegard al quedarse dormido sólo durante unos instantes en su presencia. A partir de entonces sólo veía a su padre con motivo de las grandes festividades como Noruz ${ }^{63}$. Esta situación continuó hasta que Bahram, por la intervención del enviado del emperador romano $^{64}$ fue liberado y regresó con Mundar quien para él, según los versos de Ferdosi, era mejor que sus padres ${ }^{65}$.

Seguidamente, Ferdosi pasa a narrar la muerte de Yazdegard. Los astrólogos pronosticaron que este rey perecería a las orillas de un río llamado Su, ubicado en Tus. Por ello, Yazdegard decidió no acercarse jamás a dicho lugar para evitar la muerte, hasta que enfermó, sangrando por la nariz. El Mubed dijo a Yazdegard que el motivo de su enfermedad se debía a su deseo de huir de la muerte, recomendándole que fuera hasta aquel río y le

61 Abolghasem Ferdosi... شاهنامه (=Libro de los reyes...), vol. VII, pp. 264-269.

62 Al-Ṭabarī,... تاريخ (= La historia...), vol. II, pp. 610 y 614. Consulten también: Ta ${ }^{e} a l a b i \overline{1}, \ldots$ غرر (= La historia ...), p. 348-349.

63 Fiesta que marca el inicio del año nuevo persa.

64 Según otras narraciones históricas, el enviado que había llegado a Persia para establecer un pacto fue el hermano del emperador romano, véase: Al-Ṭabarī,... تاريخ (=La

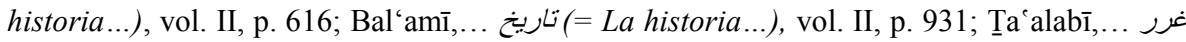
(= La historia ...), 352. Este emperador romano podría ser Teodosio II, quien según Procopio se encontró bajo los cuidados de Yazdegard I por la voluntad de su padre, Arcadio, véase: Procopio de Cesarea, Historia de las guerras. Libros I-II, Guerra Persa. Traducido al español por Francisco Antonio García Romero, Madrid: Gredos, 2000, pp. 37-38.

65 Abolghasem Ferdosi... شاهنام (= Libro de los reyes...), vol. VII, pp. 277-281. Véase esta historia, con pocas diferencias, en: Ta ${ }^{\circ} a l a b \overline{1}, \ldots$ غر (=La historia ...), pp. 351-352. 
pidiera disculpas a Dios. Yazdegard aceptó, se dirigió al río Su y recordó a Yazdan. Pero en cuanto que sanó de su enfermedad, volvió a abandonar las plegarias. En ese mismo instante salió un caballo de las aguas del $\mathrm{Su}$ y tras acabar con la vida del rey impío se desvaneció en el horizonte de las aguas. Ferdosi narra el fin del reinado de Yazdegard con el siguiente verso: «seguir la religión sería mejor que pecar y cómo una persona puede llegar a este nivel» ${ }^{66}$.

También Bahram, según los versos del mismo poeta, reconoció que su padre era impuro, no sabio, ni adorador de Yazdan. Por esta razón cometió muchos males y siguió el camino de los daevas, tal como lo hicieron Yamshid y Kavoos ${ }^{67}$. Estos dos últimos reyes son conocidos en la tradición perso-islámica como seguidores de los daevas, por presentarse como dioses $^{68}$. Sin embargo, a pesar de que Ferdosi habla de los intentos de Yazdegard por huir de la muerte y de sus impiedades, no hemos encontrado ninguna noticia acerca de que este rey se presentara como un dios. Intentando esclarecer el motivo de esta comparación, se debe señalar que fue realizada durante la época antigua o el medioevo, cuando las personas no seguían normas universales establecidas según sus propias experiencias, adquiridas a lo largo de los siglos y por lo mismo comprendidas por todos los pueblos. En aquellos tiempos, conceptos como bien y mal, virtud y pecado, justo e injusto provenían directamente del apartado ético de cada pueblo, que a su vez se originaban en la religión que seguía. Por ello, dependiendo de la diversidad de religiones y cultos, estos conceptos

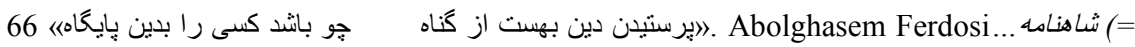
Libro de los reyes...), vol. VII, pp. 282-284 y 285.

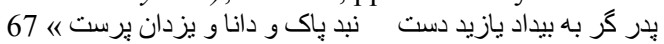

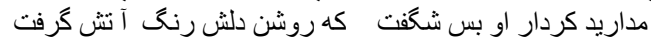

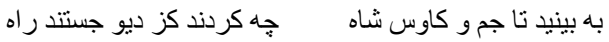

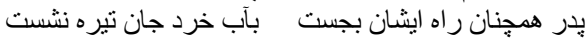

(= Si mi padre actuó con maldad, porque no era puro, ni sabio, ni adorador de Yazdan. No os sorprendáis de sus actos porque su puro corazón se volvió oscuro. Fijaos en lo que hicieron Yamshid y el rey Kavoos en cuanto que optaron por el camino de los daevas. Mi padre siguió el mismo camino y no purificó su alma oscura con el agua de sabiduría». Abolghasem Ferdosi... شاهنام (= Libro de los reyes...), vol. VII, p. 408.

68 Véase los detalles sobre cómo Yamshid se presentó como dios en: Al-Ṭabarī,... تاريخ (= La historia ...), vol. I, pp. 118-119; Abolghasem Ferdosi,... شاهناما (= Libro de los reyes...). Supervisado por E. E. Berthels, Moscú: Danesh, 1960, vol. I, pp. 42-43; Ta a'alabī,... غرر (= La historia ...), pp. 16-17. Véase los detalles sobre cómo Kavoos se reconoció como dios en: Abolghasem Ferdosi,.... شاهنام (= Libro de los reyes...). Editado por E. Berthels, L. Goozlian, M. Osmanov, U. Osmirnua, E. Taheryanov, Moscu: Danesh, 1962, vol. II, pp. 151-154. Abolghasem Ferdosi, ... شاهنامه (= Libro de los reyes...). Editado por R. Aliev, supervisado por

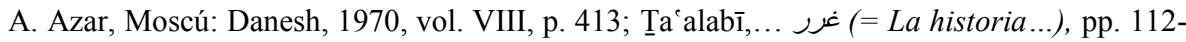
113. 
variaban de un pueblo a otro. Teniendo en cuenta esta realidad y el significado de los daevas anteriormente expuesto, podemos afirmar que cuando Bahram señala que Yazdegard optó por el camino de los daevas, se refiere a que este rey siguió normas distintas a las establecidas por los representantes de la fe estatal. En otro sentido, quizá hable de un cambio en el credo religioso de este rey, en el que tal vez influyó su esposa judía.

En realidad, el único rasgo común entre Yazdegard, Yamshid y Kavoos que hemos podido establecer según las fuentes de las que disponemos, es que los tres contrajeron matrimonio con mujeres no-iranias. Según (بند هِ (آفرينش بنيادين (= Bondhesh, (el comienzo de la creación), cuando el farr ${ }^{69}$ se separó de Yamshid contrajo matrimonio con una daeva ${ }^{70}$, es decir, con una mujer que seguía una fe distinta. Asimismo, Kavoos se casó con una mujer semita, a la que convirtió en la bānbishn (= Reina de las reinas) de su harén $^{71}$, pero antes de reclamarse como Dios.

Respecto a Yazdegard no sabemos cuándo contrajo matrimonio con su esposa judía. Podemos aventurar que sería a principios de su reinado, si tenemos en cuenta el momento en que cambió su actitud con respecto a los líderes religiosos. A través de todo esto pretendemos afirmar, que en la desviación de estos tres reyes del camino conformado a partir de los patrones persas y esencialmente de la religión irania, influyeron sus esposas no-iranias. Mujeres a las que estos reyes jamás tendrían que haberse acercado según las enseñanzas religiosas contenidas en دين كرد (= Los actos de la religión). En este texto se ordena a los iranios alejarse de los no-iranios por su naturaleza; unirse a los mazdeístas, los dioses y separarse de los

69 En realidad el farr o el farr kiani era una gracia que se transmitía de padre a hijo de forma hereditaria, y solo aquellos que lo poseían podían gobernar en Persia. Algo muy parecido a lo que Max Weber califica como carisma hereditario. Véase: Max Weber, Economía y sociedad..., p. 198. El farr kiani, según el Avesta, «pertenece a los dioses celestiales y mundanos y a todos los mesías, los que han nacido y los que todavía no, a saber: quienes renovarán este mundo», véase:... اوستا (=El Avesta...). Traducido y editado por Jalil Doostkhah, vol. I, كيان يشت (= La alabanza a los kianíes), p. 488, párrafo XXII. Cabe resaltar que los dioses mundanos son los mismos reyes. Véase: Arthur Emanuel Christensen, L'Iran ..., pp. 189-190, 288 y 320. Consulten también: Touraj Daryaee, Sasanian..., pp. 6, 34 y 70. El farr pertenecía a Yamshid hasta que mintió, motivo por el cual se separó de él, a partir de este momento no pudo resistir ante sus enemigos, a saber, los daevas. Este Farr fue cogido por Mitra, Fereydoon y Gashtasep. Véase:.... (وست (=El Avesta ...). Traducido y editado por Jalil Doostkhah, vol. I, كيان يشت (= La alabanza a los kianíes), pp. 490-491, párrafos XXXIV-XXXVI y XXXVIII.

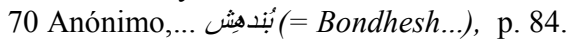

71 Sobre el matrimonio de Kavoos con esta mujer, véase: Abolghasem Ferdosi... شاهنامه (=Libro de los reyes...), vol. II, pp. 131-146; Ta alabī,... غرر (= La historia ...), pp. 107-111. 
daevas $^{72}$. Además, advierte de las consecuencias de no respetar estas disposiciones con las siguientes palabras:

El que pactara fraternidad con ellos y se les aproxime, de modo que se convierta en su compañero de alma, se reducirá su bondad, se impurificará su naturaleza, decaerá su moralidad y se extinguirá su farr $<$ divino $>^{73}$.

Precisamente eso era lo que les sucedió a estos tres reyes según la perspectiva religiosa persa. No obstante, tenemos que dejar claro que estos no fueron los únicos reyes que contrajeron matrimonio con mujeres noiranias. El mismo Ardashir I (226 - 240/1 d. C.), fundador de la dinastía sasánida, según al-Mas ūōī tenía ascendencia materna judía ${ }^{74}$. Esta mujer sería Irajt, la esposa judía de Bahman. Incluso según algunos, a causa de la influencia de esta mujer, Bahman se convirtió al judaísmo pero después dejó de practicar esta religión ${ }^{75}$. Justamente eso, es decir, el no regresar a la religión ancestral marcaría la diferencia entre los tres reyes mencionados y otros que tenían esposas no-iranias.

En relación con Yazdegard, podríamos decir que a través de Shushindojt llegaría a conocer el judaísmo y quizá se convirtiera a esta religión. Por ello se reconocería como no adorador de Yazdan, ni sabio ${ }^{76}$, y sobre todo no seguidor de la religión. Aparte de los datos de Ferdosi, existen otros que enfatizarían la posible conversión de Yazdegard al judaísmo como tener buenas relaciones con los rabinos y judíos, asunto que destacan tanto Christensen como Dayaee ${ }^{77}$. El Talmud atestigua que este rey se encontraba acompañado por los rabinos dentro de su corte. Según esta fuente judía, en una ocasión, cuando el rabino Hanna $b$. Nathana se encontraba ante este rey sentado, el mismo Yazdegard se acercó a él y colocó bien la faja de este rabino con un gesto que parecía a una inclinación ${ }^{78}$. Por lo mismo, los rabinos respondían el afecto de Yazdegard hacia ellos y la comunidad judía,

72 Véase: Anónimo,... دين (= Los actos ...), vol. III, segunda parte, p. 103.

73 Anónimo,... دين (= Los actos...), vol. III, primera parte, p. 65.

74 Al-Mas' ūdī,... مروج (=Prados...), vol. I, p. 242.

75 Al-Dīnwarī,.... خَار (= Noticias...), p. 51.

76 El sabio es quien escoge la religión mazdeísta: Anónimo,... دين (= Los actos...), vol. III, primera parte, p. 136. Y según Ferdosi, el sabio es el quien sigue a Yazdan: Abolghasem Ferdosi... شاهنامه (= Libro de los reyes...), vol. IX, p. 17.

77 Arthur Emanuel Christensen, L'Iran ..., p. 197; Touraj Daryaee, Sasanian..., pp. 21 y 78.

78 Véase: The babylonian Talmud. Editado y traducido al inglés por Dri Epstein, Londres: The Soncino Press, 1948, Zebahim Menahoth 19. a, p. 94. 
protegiéndole, eso se percibe a través de la misma fuente judía, narrando que un día:

\begin{abstract}
Amemar, Mar Zutrá y el rabí Ashí se hallaban sentados frente a la puerta del rey Ietsdeguerd [=Yazdegard], cuando pasó junto a ellos el sirviente de mesa del rey. El rabí Ashí, viendo que Mar Zutrá [61 b] se había puesto pálido, tomó un poco con un dedo y se lo puso en la boca. -¡Echaste a perder la comida del rey! -le dijo el otro. -¿Por qué lo hiciste?- le preguntaron. -Dijo él: El que la preparó hizo la comida del rey inaceptable. -¿Por qué?- Veo cerdo [leproso] allí. -Buscaron y no encontraron nada. Le puso el dedo encima y dijo ¿Mirasteis aquí? - Buscaron allí y lo encontraron.- ¿Por qué esperabas que se produjera un milagro? -le preguntaron los rabíes. -Vi - contestó- el espíritu de la lepra volando sobre él ${ }^{79}$.
\end{abstract}

Aunque según las aclaraciones del Talmud, el rabino Ashí quería proteger a Mar Zutra de la lepra ${ }^{80}$, en realidad esta actitud iba encaminada a salvar a Yazdegard.

En la misma medida que este rey persa respetaba y protegía a las minorías religiosas, facilitándoles incluso el acceso a la corte, como en el caso de los rabinos, limitaba el poder de la clase religiosa para intervenir en los asuntos de Estado. Según Nezamolmolk, desde el inicio de la formación del imperio sasánida, todos los súbditos podían llevar sus quejas ante el rey durante dos grandes festividades, Noruz y Mehregan ${ }^{81}$, momentos en los que el rey era juzgado por el Mowbedan mowbed. Yazdegard I abolió esta norma $^{82}$, con lo que redujo la posición del máximo líder religioso a un nivel inferior al del rey. Otras de las medidas impulsadas por este monarca atentaban directamente contra la estricta reglamentación zoroástrica, como la de consentir que los cristianos enterraran a sus muertos, un sacrilegio,

79 El Talmud de babilonia. Traducido y editado al español por Abraham J. Weiss, Buenos Aires: Acervo Cultural Editores, 1977, Ketuvot a-b, p. 245. Lo que aparece entre los primeros corchetes es una aclaración nuestra.

80 El Talmud..., Ketuvot a-b, p. 245, nota n. 265.

81 Los persas celebraban una gran fiesta llamada Mehregan el día 16 del mes de Mehr que coincide con el día 8 de octubre, porque creían que Mehr, es decir, el sol apareció en este día. Véase: Abū Rayḥan Muḥammad ibn Aḥmad al-Bīrūnī, ثآ آثار الباقيه (= Las obras perduradas). Traducido al persa por Akbar Dana Seresht, Teherán: Amir Kabir, 2010, p. 337. Según las creencias persas, en este día el rey pishdadi Ferydoon liberó a los persas del yugo del usurpador Zahak, véase: Ta a alabī, ... غرر (= La historia ...), p. 31.

82 Nezamolmolk,.... سبر (= La trayectoria ...), pp. 57-58. Esta historia aparece también en: Arthur Emanuel Christensen, L'Iran ..., pp. 217-218. 
como vimos, contra la tierra ${ }^{83}$. Esta medida no sólo habría afectado a los cristianos, sino también a los judíos, que practicaban, según se ha expuesto anteriormente, el ritual de la inhumación.

De modo que Yazdegard también mantuvo una actitud favorable hacia los cristianos. Un comportamiento que fue considerado por Christensen, entre otros especialistas, como una táctica política para conservar el poder y mantener la paz con el Imperio Romano ${ }^{84}$. Esta hipótesis lleva a pensar que su respeto hacia los judíos, quienes, recordemos, no dependían de ningún poder exterior ${ }^{85}$ que amenazara los intereses del Imperio Sasánida, podría estar vinculado a ciertas simpatías personales de este rey al judaísmo.

En relación con el calificativo de pecador dado a este rey, Boyce destaca que estuvo motivado por «su comportamiento favorable hacia los herejes» ${ }^{86}$, a lo que cabría añadir, teniendo en cuenta la argumentación que venimos sosteniendo, los seguidores de otras religiones. Y sin embargo, Yazdegard I no fue el único rey sasánida que dio libertad a las minorías religiosas y trató de reducir el poder de la clase religiosa y la nobleza. Tenemos como ejemplo el caso de Ormoz IV (579 - 590 d. C.), quien no sólo dejó libres a las minorías religiosas para que practicaran sus $\operatorname{cultos}^{87}$, sino que -según Ferdosi- acabó con tres dastvares y ministros de su padre e incluso con el Mowbedan mowbed ${ }^{88}$. Pese a ello, a Ormoz IV no se le motejó de pecador y sobre todo traidor a su religión, calificativos que sí se le dieron a Yazdegard. Todo ello nos lleva a pensar de nuevo en la posibilidad de una conversión al judaísmo por influencia de su esposa.

Como era de esperar, las disposiciones de Yazdegard, contrarias a la religión estatal, suscitaron una contestación por parte de los estamentos conservadores, entrándose en una dialéctica de acción-reacción entre los poderes real y religioso. Esta idea es la que se desprende de la lectura de los versos de Ferdosi. El poeta no escatima la crudeza en sus descripciones al

83 Mary Boyce, Zoroastrians..., p. 151.

84 Arthur Emanuel Christensen, L Iran ..., p. 197; Abdol-Hosein Zarrinkoob y Roozbeh Zarrinkoob,...تاريخ (= La historia...), pp. 44-45. Sobre el comportamiento favorable de Yazdegard hacia los cristianos, véase: Arthur Emanuel Christensen, L'Iran ..., pp. 195 y 196197.

85 El único reino que había adoptado el judaísmo como religión en las inmediaciones de la Persia sasánida, fue Jazaria. Entre las fuentes religiosas persas, esta información aparece mencionada en: Anónimo,.. دين (= Los actos...), vol. III, primera parte, p. 55. Sin embargo, la instauración de este reino en Cáucaso se remonta al siglo VI d.C. Véase: Arthur Emanuel Christensen, L'Iran ..., p. 320. Este dato es el que nos lleva a afirmar que durante el período que nos ocupa, los judíos persas no contaban con el apoyo de ningún reino.

86 Mary Boyce, Zoroastrians..., p. 151.

87 Véase: Al-Ṭabarī,... تاريخ (=La historia ...), vol. II, p. 725.

88 Abolghasem Ferdosi,... شارهنامه (= Libro de los reyes...), vol. VIII, pp. 319-328. 
aludir a las mutilaciones con las que fueron castigados algunos que se quejaban del evidente mal trato recibido ante el sucesor de Yazdegerd $^{89}$. Según lo apuntado anteriormente, los reyes sasánidas solo dos veces al año, durante los festivales de Noruz y Mehregan, escuchaban las quejas de todo el pueblo. Ninguna de estas fiestas se celebraba en el mes de Jordad ${ }^{90}$ cuando Bahram, según Ferdosi, subió al poder ${ }^{91}$, lo que nos ha llevado a afirmar que estos «mártires zoroástricos» pertenecían a las capas altas, quienes podían elevar sus quejas ante el rey en cualquier fecha del año.

La descripción de la muerte de Yazdegard en las fuentes perso-islámicas también contribuye en nuestra suposición sobre la posible conversión de este rey al judaísmo. En estas fuentes, el reinado de Yazdegard termina con su muerte a causa del ataque de un caballo - dato compartido entre todos historiadores musulmanes a excepción de al-Dīnwari ${ }^{-92}$ - que desapareció tras haber dado el golpe mortal al «rey pecador». El caballo se convertía en un instrumento de Ahura-Mazda para salvar a su pueblo de la impiedad. Eso es lo que destacan al-Tabarī y Ta Ta $^{2}{ }^{2}{ }^{-13}$ entre otros ${ }^{94}$ y nos hacen comprender las narraciones poéticas de Ferdosi. Según Frye esta historia no es más que un mero cuento ${ }^{95}$ que, según Nöldeke, ocultaría el asesinato de Yazdegard I por la nobleza ${ }^{96}$. En nuestra opinión la clase alta no tenía necesidad de crear historia alguna para ocultar su crimen, como tampoco lo hizo en caso de los

89 Abolghasem Ferdosi,... شاهنامه (= Libro de los reyes...), vol. VII, p. 295. Además, según otra versión histórica, Yazdegard I «marcaba el cuerpo de la clase alta». Anónimo,... (= El conjunto de historias...), p. 68.

90 El mes de Jordad coincide con 22 de mayo hasta 21 de junio.

91 Abolghasem Ferdosi,... شاهنامه (= Libro de los reyes ...), vol. VII, p. 413.

92 Al-Dīnwarī,... آخبار (= Noticias...), p. 83.

93 Según estos autores, motivados por la opresión a la que Yazdegard los sometió, la nobleza elevó sus quejas a Dios. Poco después cuando el rey se encontraba en Gorgán apareció un caballo, que intentó domar. Al sentarse sobre su lomo, pronto se cayó y murió por la coz que le dio el caballo, tras lo cual el animal desapareció como si hubiera llegado por la gracia divina. Véase: Al-Ṭabarī,....تاريخ (= La historia...), vol. II, p. 609; Ta'alabī,... غرر (= La historia...), pp. 353-354.

94 Según otros historiadores, fue un ángel que transformándose en caballo acabó con Yazdegard, véase: Ibn al-Baljī,... فارس (=اريخ (= Sobre ...), p. 74; Bal'amī,.. Listoria ...), vol. II, pp. 921-922; Nezamolmolk,... سير (= La trayectoria ...), p. 59. La versión que da Procopio, es que este rey murió a causa de una enfermedad. Procopio de Cesarea, Historia..., libros I-II, p. 38.

95 Richard Nelson Frye, The History..., p. 319.

96 Arthur Emanuel Christensen, L Iran..., pp. 198-199; Abdol-Hosein Zarrinkoob, تاريخ (بران بعد /ز اسلام (= La historia de Irán después del Islam). Teherán: Amir Kabir, 2004, p. 163. 
predecesores de Yazdegard I, nos referimos a Bahram IV y Sapor III ${ }^{97}$. Esta invención literaria, sin lugar a dudas fue otro de los medios por los cuales los magos defendían la veracidad de su fe ante las demás creencias presentes en Persia. Pues a través de este cuento justificaban que su fe estaba protegida por fuerzas sobrenaturales que acababan de forma milagrosa con sus enemigos, tal como lo hicieron con Yazdegard.

La clase pudiente tras acabar con este rey «pecador», manifestó un profundo rechazo hacia su familia. Ellos no sólo se opusieron a la ascensión de Bahram, sino que acabaron con Sapor, otro de los hijos de Yazdegard que, según Moisés de Corene, había intentado sustituir a su padre en el trono $^{98}$. Este crimen a su vez explicaría el porqué ninguno de los hijos varones de Yazdegard sobrevivía y por qué los astrólogos recomendaron al rey que mandara a Bahram donde no hubiera persas. Quizás la epidemia a la que hacían referencia no eran sino conspiraciones palaciegas para acabar con los hijos de este rey en los primeros momentos de su vida.

Narra Ferdosi cómo después de la muerte de Yazdegard, el Mowbedan mowbed, los magos, dastvares, nobles y todos aquéllos que habían sido menospreciados por él se reunieron y no reconocieron a Bahram como legítimo sucesor. Era el hijo de un «pecador» y tenía por consejero al rey de árabes. Por estas razones, eligieron a un hombre de avanzada edad, llamado Cosroes, como futuro rey de Persia ${ }^{99}$. Podríamos entender esta posición de la nobleza y la clase religiosa como un rechazo a esta rama del clan de los sasánidas, entendiendo que ésta estaba contaminada por la impureza de Yazdegard. Temían que sus sucesores siguieran la misma línea política y continuaran reduciendo los privilegios de las capas privilegiadas.

Según Ta a alabī entre los hijos de Yazdegard, el que más odios suscitaba era Bahram, ya que lo veían igual que su padre ${ }^{100}$. Quizás, lo que más reticencias causaba entre el estamento religioso era el judaísmo que habría heredado de su madre y que podría acabar con la hegemonía del zoroastrismo en el poder. Esta es una posibilidad sobre la que hasta el momento no se había reparado. Todos los especialistas contemporáneos se

97 Sapor III (382/5 - 388/90 d. C.) fue asesinado por los dirigentes de los grandes clanes y Bahram IV (388 - 399 d. C.) perdió la vida a causa de una sublevación militar. Al-Ṭabarī,... تاريخ (= La historia ...), vol. II, pp. 606-607.

98 Moisés de Corene, Historia de Armenia. Traducido al persa por Edic Baghdasarian, Teherán: Moalef, 2001, p. 268; Arthur Emanuel Christensen, L'Iran ..., p. 199; Richard Nelson Frye, The History..., p. 319; Abdol-Hosein Zarrinkoob y Roozbeh Zarrinkoob,... تاريخ (=La historia ...), p. 46; Touraj Daryaee, Sasanian..., p. 22.

99 Abolghasem Ferdosi... شاهنامه (تاريا (= Libro de los reyes...), vol. VII, pp. 285-286. Consulten también: Al-Ṭabarī,.... تاريخ (= La historia ...), vol. II, pp. 616-617.

100 Ta ${ }^{\circ} a l a b \overline{1}, \ldots$ غرد (=La historia ...), p. 354. 
han guiado por la información que aparece de manera evidente en las fuentes: lo rechazaban porque en las formas, Bahram parecía árabe ${ }^{101} \mathrm{y}$ tenía al rey lajmí, Mundar ibn Nu'aman, a uno de sus más firmes sostenedores.

Ante esta situación, el pueblo elegido para proteger a Bahram, los árabes lajmíes, cumplió con su misión, apoyando la causa de este príncipe. Comenta al respecto Ferdosi que los árabes, en protesta al rechazo de Bahram por los líderes religiosos y nobles de Ctesifonte, empezaron a crear disturbios en todo el territorio ubicado entre el desierto y la capital sasánida, capturando a hombres, mujeres y niños. Aprovechando la inestabilidad, otros pueblos como romanos e indios atacaron Persia. Cuando fueron recriminados por los persas, los árabes les respondieron que esos asaltos eran la respuesta a la decisión de no reconocer a Bahram como rey. El sucesor legítimo de Yazdegerd marchó sobre Ctesifonte al frente de treinta mil árabes, donde se sometió la elección de este príncipe a un consejo que le eligió finalmente como rey. Aun así, los persas se opusieron a su ascensión al trono, a causa del gran daño que habían recibido de manos de Yazdegerd. Bahram, apenado por esta situación, declaró que él mismo había sido objeto de los malos tratos de su padre. Se presentaba a sí mismo como un rey sabio y prometió compensar los daños causados por su padre. Asimismo, propuso que colocaran la corona en el trono, entre dos leones y quien se hiciera con ella fuera el rey de Persia. Los magos y el Mowbedan mowbed aceptaron la proposición. Pensaban que si Bahram moría, no serían culpables del magnicidio ya que se trataba de su propia decisión, pero si por el contrario sobrevivía, ello se debería a que poseía el farr. Tras hacer muchas promesas como que iba a seguir los consejos de los dastvares y dar libertad a los líderes religiosos para destronarle en plazo de un año en caso de que no cumpliera con sus promesas, Bahram acabó con los leones, tomando la corona y por ende la soberanía persa ${ }^{102}$.

Ferdosi presenta a Bahram como un verdadero zoroástrico, en contraposición a Yazdegard. Según sus versos, el nuevo rey todavía era pequeño, tenía sólo 7 años, cuando quiso aprender todo lo relacionado con el

101 Al-Ya'qūbī,...تاريخ (=اريخ... La historia...), vol. I, p. 200; Al-Ṭabarī (= La

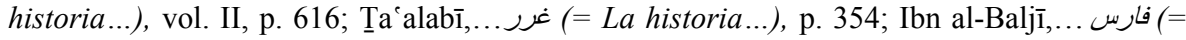
Sobre...), p. 75.

102 Abolghasem Ferdosi.... شاهنام (= Libro de los reyes...), vol. VII, pp. 287-302. Consúltese también esta historia, con pequeñas variaciones, en: Al-Ṭabarī,... تاريخ

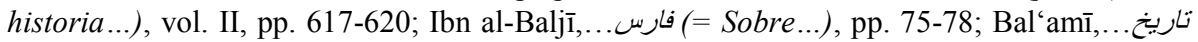
(= La historia ...), vol. II, pp. 933-939; Ta alabī,... غرس (= La historia ...), pp. 354-356. Según Christensen la anécdota de los leones fue inventada para ocultar la derrota de los persas ante los árabes. Arthur Emanuel Christensen, L'Iran ..., p. 200. 
reinado y دانش ايزدى (= la sabiduría divina), a saber: el inicio de la rectitud ${ }^{103}$, lo cual, según دين كرد (= Los actos de la religión), equivalía al mismo mazdeísmo ${ }^{104}$. Por su parte, al-Ṭabarī narra cómo Bahram, a los cinco años, quiso aprender la ley entre otras habilidades. Por lo que Mundar, el rey lajmí, encargó a los juristas persas en este aspecto de su instrucción ${ }^{105}$. Debemos entender, en el contexto de la Persia de la Antigüedad Tardía, la «ley» como sinónimo de religión, razón por la cual eran los magos quienes, según señala al-Mas 'ūdī, se encargaban de los asuntos religioso-jurídicos. No hay que olvidar que la máxima autoridad religiosa estaba investida también de la máxima autoridad jurídica ${ }^{106}$.

Estas historias presentan a un jovencísimo Bahram queriendo instruirse en los preceptos del zoroastrismo o mazdeísmo para remarcar su fidelidad a la religión ancestral de Persia y señalar así las diferencias con el reinado de su padre. En este sentido es como debe leerse la historia transmitida por Ferdosi del deseo de casarse para fortalecer la religión de Yazdan $^{107}$, es decir, la estatal sasánida.

Si se leen con atención los versos de Ferdosi, se ve cómo el poeta intenta marcar las diferencias con el período anterior, en el que había prevalecido la impiedad, señalando los actos píos protagonizados por Bahram desde su entronización. En los primeros tres días de su reinado, el nuevo rey declaró su fe en Izad único (Dios) e invitó a todos a creer en él, en la religión, la resurrección, el paraíso y el purgatorio ${ }^{108}$. Sabemos que estos conceptos relacionados con la vida del más allá son compartidos por la fe estatal sasánida con otras religiones como la judía y la cristiana. Por esta razón Ferdosi, en los versos siguientes, intenta dejar muy claro el credo de Bahram

103 Abolghasem Ferdosi... شاهنامه (= Libro de los reyes...), vol. VII, pp. 269-270.

" El inicio de la rectitud es la sabiduría divina y bendecido el es quien disfruta de la buena razón y juicio)». La misma referencia, p. 270.

104 Anónimo, ... دين (= Los actos ...), vol. III, segunda parte, p. 22.

105 Al-Ṭabarī,... تاريخ (= La historia...), vol. II, pp. 614-615.

106 Al-Mas 'ūdī,... مروج (= Prados...), vol. I, p. 240. Véase también: Nezamolmolk,.... سير (= La trayectoria...), p. 57; Arthur Emanuel Christensen, LIran ..., pp. 83, 216, 218 y 233; Touraj Daryaee, Sasanian..., p. 132.

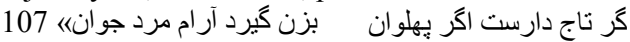

(= La mujer calmará al joven hombre independientemente de que pertenezca a la realeza o la nobleza, así se fortalece la religión de Yazdan, que con bondad guía al joven hacia la rectitud)». Abolghasem Ferdosi... شاهنامه (= Libro de los reyes...), vol. VII, p. 272.

108 Abolghasem Ferdosi... شاهنامه (= Libro de los reyes...), vol. VII, pp. 304-305. 
al reconocerse como seguidor de la fe de Zoroastro y promete que no profesaría otra religión distinta a la de sus ancestros ${ }^{109}$.

Por lo mismo, según el Shahnameh, Bahram dejó la justicia a cargo de Mowbedan mowbed desde el inicio de su reinado y siempre se encontraba acompañado por los líderes religiosos. Ellos eran quienes lo orientaban en todo y ejercían como sus ministros ${ }^{110}$. Esta sería la razón por la cual Bahram decretó mantener puros el agua y el fuego, limitando el contacto con estos dos elementos a los hirbades. Del mismo modo, prohibió el sacrificio de las vacas ${ }^{111}$, ordenó desenterrar a los muertos ${ }^{112}$ y se consideró responsable de encaminar a todos los que seguían religiones equivocadas hacia la verdadera $\mathrm{fe}^{113}$, es decir, la estatal. De igual manera prestó atención a los templos del fuego especialmente al de Azargoshasp, donde se encontraba el fuego de Zoroastro. Él engastó este santuario con las joyas de la corona de Jaghan chino (el rey de los heftalitas). Además, fue en este mismo templo donde Sepinud, hija del rey indio y la bānbishn del harén de Bahram, fue iniciada en los preceptos de la religión mazdeísta ${ }^{114}$.

Soy seguidor de la religión del profeta Zoroastro y no optaré por otro camino distinto al de mis ancestros.)» Véase: Abolghasem Ferdosi.... شاهنامد (= Libro de los reyes...), vol. VII, p. 306.

بفرمود تا هرك بد دادجوى سوى موبد موبد آورد روى «ـ Ordenó que quien reclama justicia, se dirija hacia el Mowbedan mowbed)». Abolghasem Ferdosi... شاهنامه (= Libro de los reyes...), vol. VII, p. 309. En relación con la compaña de los representantes de la religión sasánida con Bahram véase en esta misma obra, a modo de ejemplos: pp. 324, 325, 327, 329, $331,335,336,337,342,346,348,349,359,370,379,386,401,404-407,408,448$ у 452.

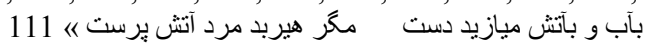

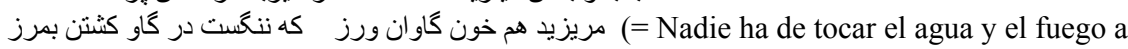
excepción del hirbad que adora el fuego. No sacrifiquéis a las vacas que es una deshonra)». Abolghasem Ferdosi,... شاهنامه (= Libro de los reyes...), vol. VII, p. 410.

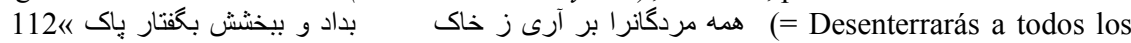

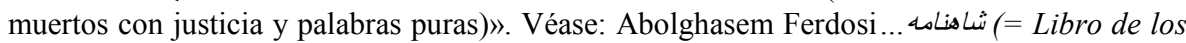
reyes...), vol. VII, p. 441; G. Hoffmann, Auszüge aus syrischen Akten persischer Märtyrer. Leipzig: In Commission Bei F. A. Brockhaus, 1880, p. 39, citado por: Mary Boyce, Zoroastrians..., p. 152. Según Daryaee el rey persa que desenterró a los muertos podría haber sido tanto Bahram V como su sucesor. Véase: Touraj Daryaee, Sasanian..., p. 66.

(ت توانكر كنم مرد درويش را بدين آورم جان بد كيش را Cubriré las necesidades de los pobres y guiaré al alma que ha optado por seguir malas religiones, hacia la fe). Véase: Abolghasem Ferdosi... شاهنامه (=Libro de los reyes...), vol. VII, p. 374.

114 Abolghasem Ferdosi.... شاهنامه (= Libro de los reyes...), vol. VII, pp. 371, 388, 396, 397, 398 y 441. En relación con el matrimonio entre Bahram y Sepinud y cómo huyó con ella de la India, véase: pp. 428-429 y 432-438 de la misma obra. Otra versión histórica presenta a esta reina india con el nombre de Sinvaz. Anónimo,... مجمل التواريخ El conjunto de historias...), p. 70. El fuego de Azargoshnasp pertenecía a los militares y era uno de los tres fuegos que según las creencias persas, existían desde el inicio de los tiempos y vigilaban toda la creación. Anónimo,... بُنبدِ (= Bondhesh...), pp. 66, 90 y 91. Según otra versión, Bahram ofreció las joyas de la corona del Jaghan de China al templo del fuego ubicado en Shiz de 
Esta política implantada por el sucesor de Yazdegard, tan opuesta a la suya, marcada por una orientación filo-zoroástrica, hizo que Bahram sea presentado en el Shahnameh como conocedor y adorador de Yazdan, un verdadero zoroástrico ${ }^{115}$, amén de ser él quien acabó con las malas religiones ${ }^{116}$. La imagen favorable transmitida por los versos de Ferdosi considera al Shahanshah como maestro de la religión y le sitúa incluso al mismo nivel que el Mowbedan mowbed ${ }^{117}$.

Curiosamente, en las fuentes perso-islámicas no vemos ninguna mención a Shushindojt. En la obra de Ferdosi, es el mismo Bahram quien se presenta como tataranieto del rey/reina Shamiran por parte materna ${ }^{118}$. El autor del Shahnameh sólo nos da este nombre, sin mencionar nada más acerca de este personaje. Sin embargo existen datos sobre Shamiran en otras fuentes. En نوروزنامه =El libro de Noruz), por ejemplo, aparece un Shamiran como familiar de Yamshid, que gozaba de cierto poder económico y social, teniendo todo el Jorasán bajo su dominio ${ }^{119}$. Asimismo existe otra Shamiran quien según مجمل التواريخ و القصص (= El conjunto de las historias y cuentos), es la propia reina Homa, hija de Bahman ${ }^{120}$. Ambos personajes, siendo el

Azerbaiyán y encargó a la mujer de dicho soberano vigilar aquel templo. Al-Ṭabarī,... تاريخ (= La historia...), vol. II, pp. 622 y 623. Consulten también: Bal'amī,... تاريخ (= La historia ...), vol. II, pp. 942 y 943; Ta ${ }^{a} a l a b \overline{1}, \ldots . .$. (La historia ...), p. 360; Arthur Emanuel Christensen, LIran..., p. 120. Según esta última referencia el templo de fuego ubicado en Shiz, es el mismo Azargoshnasp.

115 Abolghasem Ferdosi... شاهنامه (= Libro de los reyes...), vol. VII, pp. 310, 383, 393, $395,398,400$ y 415.

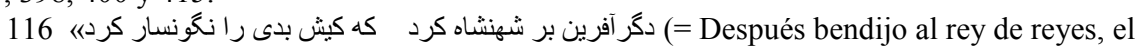

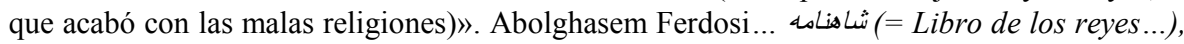
vol. VII, p. 364.

(= Alteza, excelencia y maestro de la religión que dominas en todo el mundo y eres el Mowbedan mowbed)». Abolghasem Ferdosi... شاهنامه (= Libro de los reyes...), vol. VII, p. 385. Consulten también la página 358 de la misma referencia. Según el Avesta el término $د$ que se pronuncia como Rad, significa maestro de la religión. Véase:.... اوستا (= El Avesta...). Traducido y editado por Jalil Doostkhah, Hat XIII, vol. I, p. 158, párrafo III.

118 Abolghasem Ferdosi... شاهنامه (=Libro de los reyes...), vol. VII, p. 296.

119 Según la obra de Jayyam, la invención del vino estaría relacionada con este Shamiran. Según cuenta, este rey tenía un hijo llamado Badam, que mató con una flecha a una serpiente enroscada alrededor del cuello de un ave quebrantahuesos, salvando así la vida de este último. Al año siguiente, en el mismo día aparece, el pájaro al que había salvado y deja algunas semillas ante el rey. Shamiran ordena que las planten y germinan unas parras. De los racimos de uvas extraen el jugo, que conservan en vasijas de arcilla, fermentando con el tiempo aparece por primera vez el vino. Véase: Omar Jayyam, نوروزنامه رساله اي در منشاء و تاريخ El libro de Noruz, un texto sobre el origen, la historia y los rituales de Noruz). Editado por Mojtaba Minovi, Teherán: Matbae Roshanai, 1933, pp. 65-70.

120 Anónimo,... مجمل التواريخ (= El conjunto de historias...), p. 30. 
primero uno de los contemporáneos de Yamshid, rey perteneciente a la dinastía pishdadi - la primera que gobernó en Persia según la tradición histórica- y el segundo personaje una reina de los kianíes -la segunda dinastía que gobernó en esta tierra según la misma tradición ${ }^{121}-$, son ancestros bastantes lejanos para que Bahram fuese su tataranieto. Lo que se buscaría por medio de esta genealogía es presentar para Bahram una ascendencia irania pura y borrar cualquier atisbo del legado semita -judíoen las listas de gobernantes de Iranshahr.

Además en el Shahnameh aparece una anécdota que trata de reflejar el modo del cual eran percibidos los judíos por Bahram. Según Ferdosi narrando su relato de forma resumida y con nuestras propias palabras-, durante el transcurso de una de sus cacerías de leones, Bahram se encontró con un anciano quien le contó una historia acerca de dos hombres de su tierra: Beraham, un rico y tacaño judío y Lonbak, que hasta el medio día se dedicaba a vender agua y por la tarde invitaba a todos aquellos que quedaban en el camino. El rey, movido por la curiosidad, quiso conocer a ambos hombres. Con este deseo en mente, prohibió a todos comprar agua de Lonbak. Después, haciéndose pasar por miembro de la guardia real que había perdido al rey, buscó refugio en la casa del vendedor de aguas durante tres noches. La primera noche, Lonbak tras aceptarlo con los brazos abiertos, le dio un masaje, lo entretuvo con el ajedrez y le ofreció cena y vino. Al día siguiente, al no vender el agua, vendió su propia ropa y con el dinero obtenido compró carne y preparó otra comida para su invitado. Al tercer día y como seguía sin vender agua, empeñó el almizcle y unos instrumentos de su trabajo y con el dinero adquirido, preparó otra comida para su huésped. Bahram impresionado por la hospitalidad de Lonbak, se despidió de él. Acto seguido, se presentó en la casa de Beraham, el judío, esta vez haciéndose pasar por un militar que se había extraviado durante la cacería real. Con la excusa de tener una casa muy estrecha, el judío no aceptó a Bahram y sólo le dejó dormir sin comida a la puerta de su casa, con la condición de limpiar los excrementos de su caballo y pagar la indemnización en caso de que su animal rompiera alguno de los azulejos de su mansión. Después el judío, ya en el interior de su hogar preparó una buena mesa y se dedicó a disfrutar de aquellos manjares, sin preocuparse por Bahram, que intentaba dormir en aquellas pésimas condiciones. Al día siguiente, Bahram madrugó y decidió irse, pero el judío le recordó que tenía que limpiar los excrementos de su caballo. Bahram le pidió que encargara a alguien que los limpiara, que él mismo lo pagaría, pero el judío se negó. Por ello, Bahram sacó un pañuelo

121 Según Pirnia el reinado de Homa no coincide con los hechos reales históricos. PIRNIA, Moshir od-Dowleh,... يران باستان (= Irán antiguo ...), vol. IV, p. 2161. 
de seda lleno de almizcle de su zapato y con él se puso a limpiar los excrementos de su caballo. Al día siguiente Bahram, en su calidad de rey, convocó a ambos, al judío y al vendedor de aguas, a su corte y ordenó que le requisaran la gran riqueza al judío, regaló parte de ella a Lonbak, el buen anfitrión y dejó solo cuatro dirhames al judío después de criticar su religión ${ }^{122}$.

Como fácilmente se puede inferir, ambos personajes son prototípicos, analizamos sus características desde la perspectiva de la religión mazdeísta. El buen anfitrión, Lonbak, es el modelo de hombre que ama al prójimo, naturaleza más zoroástrica ${ }^{123}$. Por tener generosidad, aceptar y atender a los desamparados, cumplía con los mejores actos, aquellos que aproximaban al hombre al paraíso. Además su alma bondadosa tras la muerte se valoraría por lo mismo ${ }^{124}$.

En contraposición a Lonbak se halla el judío, Beraham, modelo de hombre que no amaba al prójimo, es decir, contaba con una naturaleza no zoroástrica. Al no ofrecer nada a su invitado participaba en aumentar el poder del daeva de mentira ${ }^{125}$. Después de la muerte, su alma al contrario que la de Lonbak sería reprochada por no dar cobijo a quien se lo demandó $^{126}$ y por lo mismo, sería castigada en el purgatorio ${ }^{127}$.

Es sorprendente que, de todos los reyes sasánidas, sólo se cuente una anécdota como esta de Bahram. Tal vez esto esté motivado por el origen judío de su madre y la posible práctica de esta religión por parte de su padre, en la base, como ya dijimos, de su rechazo por los magos y parte de la nobleza. Tanto Ferdosi, como las fuentes que usara para escribir su gran poema épico sobre Persia, a través de esta anécdota, tratan por un lado de mostrar la superioridad de los valores éticos de la religión estatal sasánida sobre los del judaísmo. Más allá de este objetivo, buscarían presentar el rechazo por parte del rey de la herencia religiosa de su madre, recalcando su «limpieza de sangre». El hecho de que requisara los bienes a Beraham para

122 Abolghasem Ferdosi... شاهنامه (=Libro de los reyes...), vol. VII, pp. 310-319.

123 Anónimo,... دين (= Los actos)..., vol. III, segunda parte, p. 211.

124 Anónimo,... مينوى (= El espíritu...),pp. 13, 17, 18 y 54. En relación con la valoración dada a los hospitalarios tras la muerte véase también:... اوكتا (= El Avesta...). Traducido y editado por Jalil Doostkhah, vol. I, ها دخت نسك (= El capítulo Ha dojt), p. 512, párrafo XIII; Anónimo, ارداوير اف نامهام (= La obra de Arda-Viraf)», número I, pp. 9-16, espec. p. 14.

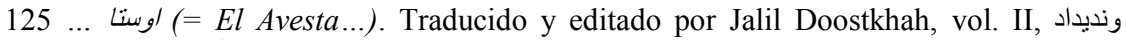
(Wandidad) فركرد هجدهم (= Fargard XVIII), pp. 852-853, párrafos XXXIII-XXXIV.

ها دخت نسك , El Avesta...). Traducido y editado por Jalil Doostkhah, vol. I) اوستا ... 126 (= El capítulo Ha dojt), p. 515; Anónimo,... مينوى (= El espíritu...),p. 15.

127 Anónimo, ارداوير اف نامهام (= La obra de Arda-Viraf)», número V, pp. 465-472, espec. pp. 468-469, párrafo LXXXIX. 
dárselos a Lonbak supone quitarles de los judíos la influencia que habían adquirido en la corte de Yazdegerd. Con todo ello Bahram pretendía restaurar la posición que la religión estatal tradicional no debería haber perdido.

Esta anécdota, junto a la ausencia de datos sobre la madre judía de Bahram en las fuentes perso-islámicas, la insistencia de Ferdosi por presentar a Bahram como un verdadero seguidor de la religión sasánida y enfrentado a las religiones no-iranias, llaman la atención y hacen que nos plateemos si realmente este rey no tenía alguna inclinación hacia la religión

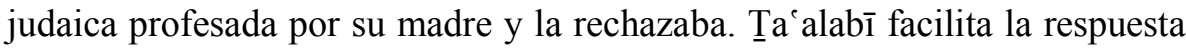
a esta cuestión cuando describe la habilidad de Bahram en distintas lenguas con las siguientes palabras:

\begin{abstract}
En la organización militar y llevar la comandancia del ejército hablaba en árabe, en el día de supervisión militar en persa, en la corte en darí, en el deporte y el juego del polo en pahleví, en la guerra en turco, en la caza en zabolí, en asuntos religiosos en hebreo, en la medicina en indio, en la astrología en romano, en la lucha en nabtí y a la hora de tratar a las mujeres hablaba con el acento harati ${ }^{128}$.
\end{abstract}

Ta ${ }^{\circ} a l a b \overline{1}$, con esta descripción, intenta subrayar que Bahram utilizaba el idioma del pueblo que a su modo de ver era el más experto en diferentes materias. Entonces, y según toda la información ofrecida por Ferdosi acerca del credo religioso de Bahram, lo natural sería que éste utilizara la lengua pahleví o avéstica en temas religiosos, pero no el hebreo. El hecho de utilizar la lengua sagrada de la Torah para asuntos religiosos, es cuanto menos llamativo e indica la fe de este rey sasánida en la religión judaica. A favor de esta hipótesis juega el hecho de que su madre tratara de recuperar el cadáver de su hijo después de su muerte ${ }^{129}$, ¿para inhumarlo de acuerdo con el ritual judío? Esta historia está presente en varios relatos, a excepción del Shahnameh de Ferdosi ${ }^{130}$. Posiblemente, tal y como señala Frye, no fuera la

128 Ta a alabī,$\ldots$ غرد (= La historia ...), pp. 357-358.

129 La muerte de Bahram está envuelta en el enigma. Las fuentes narran que el rey cayó en un pantano -según al-Dīnwarī- o en un pozo -según al-Ṭabarī y sus seguidores, Bal'amī y Ta ${ }^{`} a l a b \overline{1}$ - mientras perseguía a un onagro. Su madre ordenó que recuperaran su cadáver pero no encontraron rastros de él. Véase: Al-Dīnwarī,... آخبار (= Noticias inquietantes...), p. 86; Al-Ṭabarī,... تاريخ (= La ha ha historia ...), pp. 364-365; Bal'amī,... تاريخ (= La historia ...), vol. II, p. 950.

130 Según Ferdosi, Bahram al cumplir los 63 años murió de forma natural tras haber heredado su corona a su hijo Yazdegard. Después de su muerte colocaron su cadáver en una 
hija del exiliarca, pero de lo que no hay dudas es de su condición judía que legó a su hijo.

No obstante, Bahram, siendo judío, no sólo no se enfrentó a la clase alta como hizo su predecesor -la cual había acabado con dos reyes anteriores a su padre, con el propio Yazdegard y con los hermanos de Bahram- sino que dejó todos los asuntos públicos, especialmente los relacionados con la religión, en manos de los líderes religiosos. De ahí que la política religiosa asociada al reinado de Bahram contra los cristianos, que duró hasta el establecimiento del pacto con el Imperio Romano ${ }^{131}$, no vendría dictada por las creencias personales de Bahram sino a las de líderes religiosos. Los cuales junto a nobles, según Christensen, regían todos los asuntos de su imperio $^{132}$.

El interés de este rey judío por los lugares del culto zoroástrico, especialmente, Azargoshasp o Azargoshnasp, templo de los militares, podría provenir de su respeto a las creencias de su pueblo y de sus propios militares que seguían la religión estatal. Un respeto similar al que tenía Shirin, esposa cristiana de Cosroes II (590/1 - 628 d. C.), quien según Warner, entregó todos sus bienes a los templos del fuego por la tranquilidad del alma de su marido ${ }^{133}$. Naturalmente estas medidas adoptadas por Bahram lo convirtieron en un rey popular en las fuentes sasánidas/perso-islámicas ${ }^{134}$. Así, el autor anónimo de مجمل التواريخ و القصص Bastorias y cuentos), afirma respecto a Bahram y su reinado:

Él era el más justo entre todos sus ancestros, no ha existido, ni existirá un rey más feliz y más valiente que él. [Y] los campesinos no llegarán a experimentar la alegría y la felicidad [que] tuvieron durante su época. Él siempre estaba preocupado por la situación del mundo y nadie sufrió el dolor ni malestar durante su reinado ${ }^{135}$.

torre de silencio al estilo real. Véase: Abolghasem Ferdosi... شاهنامه (=Libro de los reyes...), vol. VII, pp. 452-454.

131 Durante el reinado de Bahram, en el año 422 d.C., se firmó un acuerdo de paz entre Persia y el Imperio Romano, según el cual tanto los cristianos de Persia como los zoroástricos del Imperio Romano pudieron practicar libremente su religión. Arthur Emanuel Christensen, LIran ..., p. 203; Touraj Daryaee, Sasanian..., p. 23.

132 Arthur Emanuel Christensen, LIran ..., p. 201.

133 Mary Boyce, Zoroastrians..., p. 174.

134 Según Christensen convirtieron a Bahram en un rey popular por haber dejado todos los asuntos a cargo de la nobleza. Arthur Emanuel Christensen, L Iran ..., p. 201. Véase al respecto: Soodabeh Malekzahe, «A Historiographical Study of The Life and Reign of Bahram V», pp. 1-10, espec. 4-5.

135 Anónimo,... مجمل التواريخ (=El conjunto de historias...), p. 69. Lo que aparece entre los corchetes es una aclaración del mismo texto. 
Al no enfrentarse Bahram con la clase alta y dejar todos los asuntos a su cargo, los autores perso-islámicos o bien no dieron importancia a la realidad de la fe que profesaba o bien, por pertenecer al movimiento de la Šu'ūbiyya como fue el caso de Ferdosi, trataron de ocultar esta realidad. Admitir cualquier atisbo de duda acerca de la absoluta fe de uno de los reyes sasánidas en la religión irania estaba directamente en contra de la ideología de este grupo que, recordemos, pretendían resaltar el elemento ario de su cultura. Precisamente, por esta razón escondieron la condición judía de Bahram y la reemplazaron por otra irania, para lo cual, no escatimaron en exageradas narraciones en las que se destacaba la fe absoluta e inquebrantable en la fe estatal sasánida de este rey, según se puede leer en la obra del poeta nacional iraní.

\section{CONCLUSIÓN}

A pesar de todos los mitos creados por los magos sobre la unión entre el poder político de Iranshahr y la religión mazdeísta/zoroástrica, que esta tierra sólo recibiría al Dios de la bondad y la alegría a través de esta religión, y el rechazo hacia todas las creencias consideradas maléficas, éstas, como el judaísmo, dejaron una huella indeleble en la historia religioso-política de Persia a través de sus seguidores, como la esposa de Yazdegard I. Ella tras su unión con este rey, entró en el escenario político, abriendo las puertas de la corte al judaísmo y a sus representantes, es decir, a los rabinos. A causa de la influencia de esta mujer y su fe, en la historia sasánida hubo un rey judío, a saber, Bahram V.

En relación con la posible conversión de Yazdegard al judaísmo, pese a tener muchas indicaciones al respecto como reconocer a Bahram como el más parecido a su padre y a Yazdegard como pecador, no seguidor de la religión, etc, no tenemos datos claros que lo demuestren o al menos hagan referencia a ello. Incluso el Shahnameh nos confunde al respecto, pues por un lado rechaza a este rey con calificativos negativos y por otro le dedica un verso en el que el mismo Yazdegard jura por el templo del fuego Jorrad Borzin y el Sol ${ }^{136}$, por los símbolos y deidades del mundo mazdeísta. Creemos que esto se debería sobre todo a las características del Shahnameh que no podía reconocer a ningún rey persa como seguidor de otra religión distinta de la irania, aunque fuese tan pecador como Yazdegard.

Creemos que hemos podido responder a la suposición de Malekzadeh, quien, antes que nosotros, había cuestionado la condición religiosa o mejor

136 Abolghasem Ferdosi... شاهنامه (= Libro de los reyes ...), vol. VII, p. 282. 
dicho, judía de Bahram sin haber encontrado una respuesta para ella ${ }^{137}$. Sin embargo, indicar claramente cuál fue la realidad de religión profesada por Yazdegard, se queda como una cuestión pendiente de resolver que demostraría hasta qué punto los reyes sasánidas creían en la religión estatal, que legitimaba su permanencia en el poder ${ }^{138}$.

137 Soodabeh Malekzadeh, «A Historiographical Study of The Life and Reign of Bahram V», pp. 1-10, espec. 2 y 4.

138 Al finalizar, agradezco a Carlos Martínez Carrasco por llevar a cabo la revisión del presente artículo. 
